\title{
Distributed Generation with Heat Recovery and Storage ${ }^{\ddagger}$
}

\author{
Afzal S Siddiqui ${ }^{*}$ Chris Marnay ${ }^{+}$, Ryan M Firestone ${ }^{+}$, and Nan $\mathrm{Zhou}^{+}$
}

\section{Abstract}

Electricity generated by distributed energy resources (DER) located close to end-use loads has the potential to meet consumer requirements more efficiently than the existing centralised grid. Installation of DER allows consumers to circumvent the costs associated with transmission congestion and other non-energy costs of electricity delivery and potentially to take advantage of market opportunities to purchase energy when attractive. On-site thermal power generation is typically less efficient than central station generation, but by avoiding non-fuel costs of grid power and utilising combined heat and power (CHP) applications, i.e., recovering heat from small-scale on-site generation to displace fuel purchases, then DER can become attractive to a strictly cost-minimising consumer. In previous efforts, the decisions facing typical commercial consumers have been addressed using a mixed-integer linear programme, the DER Customer Adoption Model (DER-CAM). Given the site's energy loads, utility tariff structure, and information (both technical and financial) on candidate DER technologies, DER-CAM minimises the overall energy cost for a test year by selecting the units to install and determining their hourly operating schedules. In this paper, the capabilities of DER-CAM are enhanced by the inclusion of the option to store recovered low-grade heat. By being able to keep an inventory of heat for use in subsequent periods, sites are able to lower costs even further by reducing off-peak generation and relying on storage. This and other effects of storages are demonstrated by analysis of five typical commercial buildings in San Francisco, California, and an estimate of the cost per unit capacity of heat storage is calculated.

\section{Introduction}

There have been many claimed potential benefits from a move from our current highly centralised power generation and delivery system towards a more distributed paradigm (see Gumerman et al. (2003)). Decentralised visions and concepts go by

\footnotetext{
‡ The work described in this paper was funded by the Assistant Secretary of Energy Efficiency and Renewable Energy, Office of Distributed Energy of the US Department of Energy under Contract No. DE-AC02-05CH11231. The lead author wishes to acknowledge the generous support of the Business Research Programme of the Michael Smurfit Graduate School of Business at University College Dublin. The authors wish to thank Kristina Hamachi LaCommare and Judy Lai of Ernest Orlando Lawrence Berkeley National Laboratory (Berkeley Lab) for their valuable research assistance. Also helpful were discussions with Owen Bailey of Cornell University and Karl Maribu of the Norwegian University of Science and Technology. All remaining errors are the authors' own.

* College Lecturer, Department of Banking and Finance, Michael Smurfit Graduate School of Business, University College Dublin, Blackrock, Co. Dublin, Republic of Ireland, tel: +353 (0)1 716 8091, fax: +353 (0)1 283 5482, e-mail: afzal.siddiqui@ucd.ie.

$+<$ Staff Scientist, Graduate Student Research Assistant, Post-Doctoral Fellow>, Environmental Energy Technologies Division, Ernest Orlando Lawrence Berkeley National Laboratory, Berkeley, CA 94720, USA, tel: +1 510486 7028, fax: +1 510486 7976, e-mail: <C_Marnay, RMFirestone, NZhou $>$ @lbl.gov.
} 
many poorly defined names including distributed energy resources (DER), distributed generation (DG), and microgrids. However, common to virtually all arguments in favour of decentralisation is the clear need in the post-industrial economies to lower the prevalence of fossil fuel sources of waste heat and other losses associated with energy conversion to electricity and its subsequent long-distance delivery to serve end-use loads, e.g., these two sources of energy loss in the US together accounted for fully $18 \%$ of all US 2003 total primary energy consumption (see EIA (2005)). ${ }^{1}$ Furthermore, losses tend to increase over time both because electricity provides a growing share of end-use energy consumption in developed economies and because fossil-fired generation tends to provide a growing share of the total fuel mix. This combination of effects is particularly powerful in the case of the US, as can be seen in Figure 1. Note that electricity generation from most sources, except oil, is growing to meet the growing demand and that fossil fuels as a group are growing faster than the total. Based on estimates for historic changes in conversion and delivery efficiency, an estimate of the total waste heat from fossil generation is shown in Figure 1. There has been fairly clear and consistent growth in waste heat production over this fortyyear historical window. Indeed, these losses offer an obvious and attractive target in the effort to increase efficiency and, equivalently, to lower carbon emissions. In order to achieve this, many have recognised the importance of the opportunity offered for waste reduction by application of combined heat and power (CHP) technology (see, for example, Blair (2004)). Because compared to electricity transmission, transporting low-grade recovered heat is prohibitively expensive relative to its net economic value, generating electricity close to potential uses for waste heat, rather than in large remote stations, has a compelling attraction. While considerable attention has been paid historically to application of CHP for provision of process heat, mostly on relatively large scales, significant penetration of CHP technology will require its application in the commercial (or even residential) sector, posing some major research challenges. Significant among these is the need to match heat delivery to variable building requirements, driven by work hours, weather, and fuel prices.

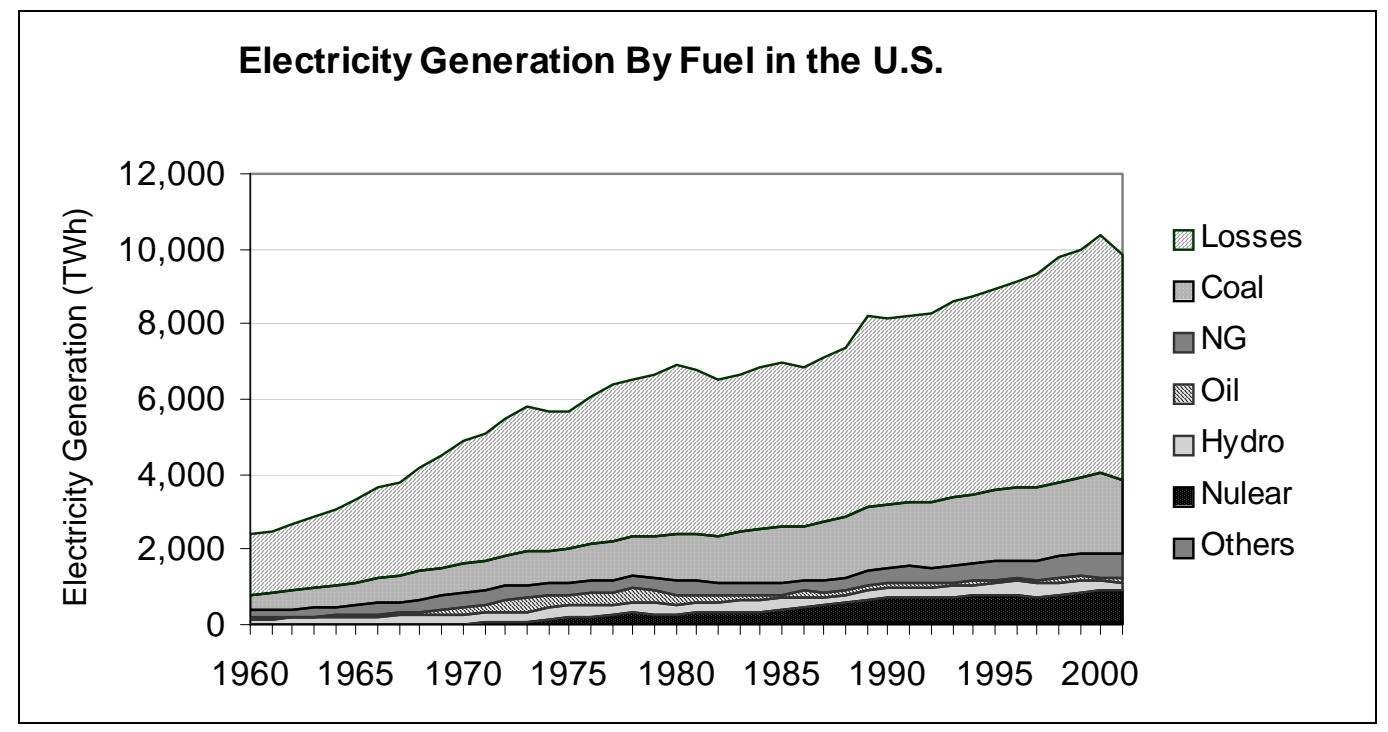

Figure 1. Growth of Fossil Fuel Based Waste Heat Production from US Power Generation

\footnotetext{
${ }^{1}$ Note this is only the waste heat from fossil generation, excluding nuclear or other renewable sources.
} 
Self-provision of electricity can be attractive simply because on-site generation avoids many of the costs associated with electricity delivery, which typically account for around half of the retail price. Also, for most commercial buildings, electricity costs far exceed heat energy costs and electricity production will provide the majority of overall customer energy bill savings from CHP; however, electricity generation on building or neighbourhood scales will usually be inefficient compared to central station generation, implying both that potentially more heat will be available than at central stations and that effective use of waste heat will play a key role in the economics of DER. When seeking methods for achieving efficient operation of DER, a long analytic tradition is available on finding efficient technology choice and operations for central station power generation without CHP, and some useful knowledge on operation of larger scale CHP systems, such as district heating systems. However, available methods for optimising operation of small-scale CHP are extremely limited, especially under variable fuel prices.

Focusing strictly on the customer economic perspective, past work has developed methods for jointly optimising heat and electricity use and production within a strict cost minimising framework, but this has been achieved under the assumption that meeting heat and electricity loads are hard constraints. While in the time steps typically used, i.e,. hourly, meeting electricity loads can be reasonably considered a hard requirement, but heat loads pose a more complex challenge because:

1. Active storage of low-grade heat will likely be economic under some circumstances and is already widely used (see, for example, Brown (2000)).

2. Over short periods, heat delivery can deviate significantly from the optimal level needed to maintain preferred indoor ambient and water temperatures. This effect derives from both occupant tolerance for short-lived deviations from desired comfort levels and from the natural thermal storage capability of buildings and water tanks, which can create a considerable lag between deviations in heat production and unacceptable ambient conditions. The thermal properties of buildings can also be adjusted to enhance their heat lag performance (see, for example, Kedl (1991) and Hittle (2002))

3. De-synchronising electricity and heat production may have a significant effect on the benefits of on-site electricity generation.

This paper addresses the first and third issues by expanding on past models to permit active storage of heat between time periods. A simple model of thermal energy storage is developed as a first step towards eventual full de-synchronisation of heat and electricity production within the complex economic and physical constraints implicit in points 1-3 above. 


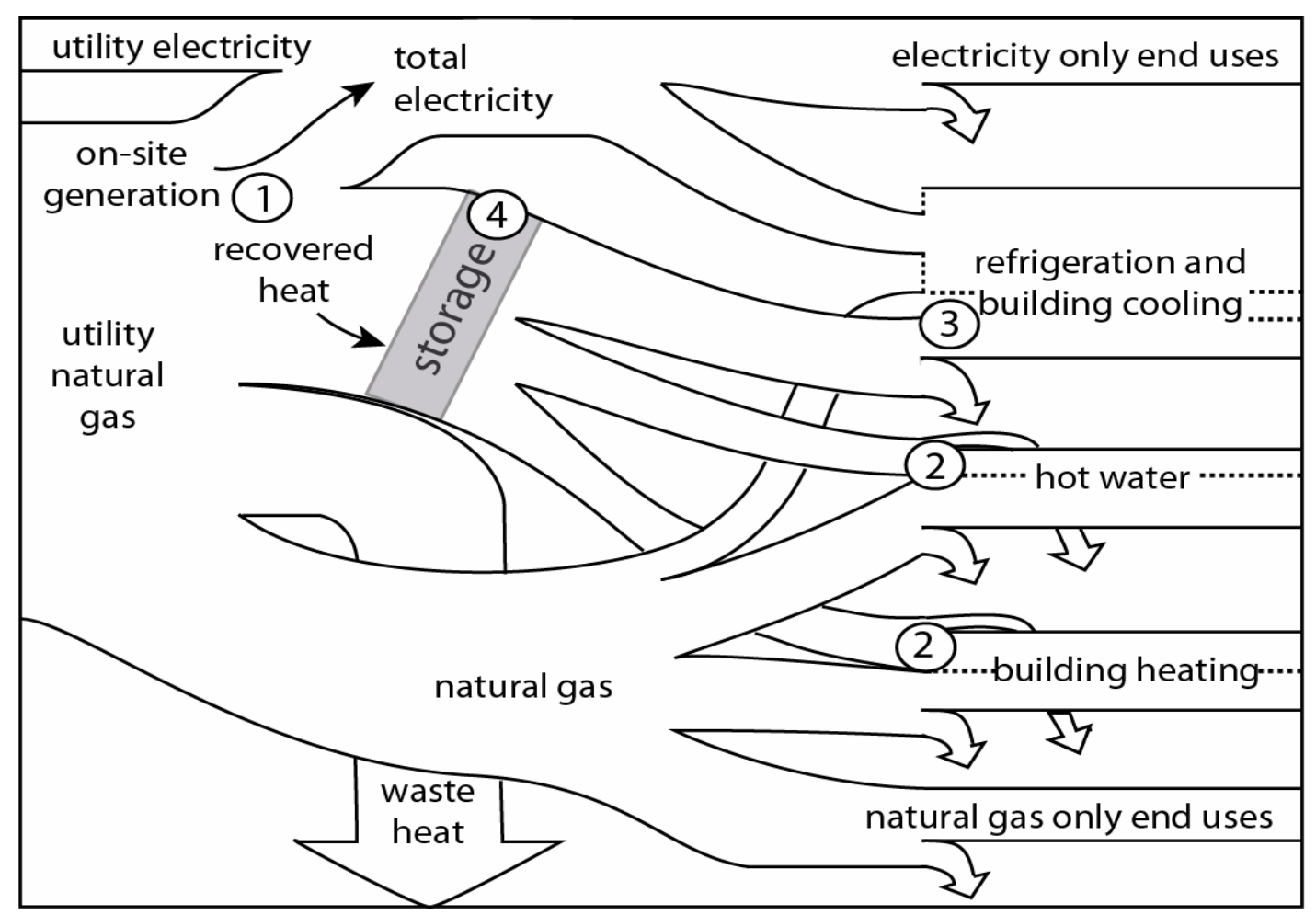

Figure 2. Energy Flows in a Commercial Building CHP Installation

The approach taken in this paper and prior work by Berkeley Lab is well demonstrated by Figure 2. In this figure, energy inflows to the building are shown on the left, and in this study, they are only utility-purchased natural gas and electricity. On the right side, useful energy flows in the building are shown. Some end uses can be served only by electricity and others only by natural gas, shown at the top and bottom. Space-heating and domestic water-heating are the traditional CHP opportunities that can be served either by direct fire of natural gas or heat recovered from the energy conversion of natural gas fuel to electricity. Finally, the cooling and refrigeration loads are by far the most important, interesting, and challenging loads for three reasons:

1. They can be met in three ways: by electricity using the familiar direct expansion (DX) air conditioning equipment, by direct fire of natural gas in absorption cycles, or by waste heat driven absorption cycles.

2. Since these loads are, in warm climates, coincident with peak electricity requirements, under time-of-use rates and/or with demand (or power) charges imposed, they are more expensive to serve than other end uses.

3. And finally, sizing equipment to meet these requirements is particularly complex because cooling equipment is relatively expensive, and if DX cooling is involved, supplemental absorption cooling allows downsizing of electrical systems.

Consequently these are the most interesting loads and the focus of research at Berkeley Lab. The approach used here and in other work is that equipment choice and operation are solved for the system shown in Figure 2 in one simultaneous problem. The sizing and operation of all equipment is, therefore, properly traded off against 
other alternatives. In prior work, the solution included optimum equipment choices and operating schedules for on-site generators, shown at " 1 " in Figure 2, for traditional CHP equipment for space and water heating, shown at " 2 " in Figure 2, and the most interesting choice of cooling and refrigeration at "3." The innovation reported in this paper is that constraints on the timing of use of waste heat have been relaxed by the addition of storage as shown in Figure 2 at "4." In particular, heat recovered from the generation of electricity can be stored by a costless storage device as shown in the figure. It can then be freely charged and discharged, with a small thermal loss being the only penalty. Once heat is recovered from storage, it can be used as in prior versions of this model. Note that the addition of storage allows heat to be passed from one period to a subsequent one, but more importantly, it frees the electricity generating schedule to take increased advantage of the time-varying opportunities for cost savings.

The structure of this paper is as follows:

- in Section 2, the input parameters and decision variables are defined, and the mathematical model is formulated

- in Section 3, the customer load data, along with utility tariff details, DER technology cost and performance criteria, and thermodynamic parameters, are indicated

- in Section 4, the main results for a variety of customer sites are presented and discussed

- in Section 5, we summarise our findings and offer directions for future research

\section{Mathematical Model}

In this section, the DER Customer Adoption Model (DER-CAM) is presented, including an overview of the present version of the model's mathematical formulation. While this model has been used extensively by Berkeley Lab researchers and results have been previously reported (see Marnay et al. (2001) and Rubio et al. (2001)), the current version additionally incorporates CHP-enabled technologies and carbon taxation (see Siddiqui et al. (2005a) and Siddiqui et al. (2005b)). All versions of the model have been programmed in the commercial optimisation software, GAMS (General Algebraic Modeling System). The results presented are not intended to represent a definitive analysis of the benefits of DER adoption, but rather as a demonstration of the current DER-CAM. Developing estimates of realistic customer costs is an important area in which improvement is both essential and possible, and is being actively pursued by the authors in other work.

\subsection{Model Description}

In its current formulation, the model purchases two fuels, electricity and natural gas, and supplies four types of end uses ${ }^{2}$, electricity only (e.g., lighting), cooling, space heating, and water heating. The model's objective function is to minimise the cost of supplying the four end uses to a specific site during a given year by optimising the

\footnotetext{
${ }^{2}$ We do not consider the natural-gas-only load of Figure 2.
} 
distributed generation of part or all of its electricity requirement. In order to attain this objective, the following questions must be answered:

1. Which distributed generation and CHP technology (or combination of technologies) should the site install?

2. What is the appropriate level of installed capacity of these technologies that minimises the cost of meeting the site's requirements for energy?

3. How should the installed capacity be operated in order to minimise the total bill for meeting the site's four end-use requirements?

The essential inputs to DER-CAM are:

- the site's four load profiles

- utility electricity and natural gas tariffs

- capital, operating and maintenance (O\&M), and fuel costs of the various available DER technologies, together with the interest rate on customer investment

- rate of carbon emissions from the macrogrid and from the burning of natural gas for on-site power generation and direct combustion to meet thermal loads

- carbon tax rates

- thermodynamic parameters governing the use of CHP-enabled DER technologies and heat storage

Outputs to be determined by the optimisation are the cost minimising:

- technology (or combination of technologies) installed and their respective capacities

- hourly operating schedules for installed equipment

- total cost and carbon emissions of supplying the total energy requirement through either DER or macrogrid generation, or typically, a combination of the two

Of the important assumptions that follow, the first three tend to understate the benefit of DER, while the fourth overstates it:

1. Customer decisions are taken based only on direct economic criteria, i.e., the only benefit that the site can achieve is a reduction in its energy bill.

2. The site is not allowed to generate more electricity than it consumes. On the other hand, if more electricity is consumed than generated, then the site will buy from the utility at the default tariff rate. No other market opportunities, such as sale of ancillary services and load interrupts, are considered.

3. Reliability and power quality benefits, and economies of scale in O\&M costs for multiple units of the same technology are not taken into account.

4. Manufacturer claims for equipment price and performance are accepted without question. Some of the permitting and other costs are not considered in the capital cost of equipment, nor are start-up losses and some other operating costs.

\subsection{Mathematical Formulation}

This section describes intuitively the core mathematical problem solved by DERCAM. First, the input parameters are listed, and the decision variables are defined. Next, the optimisation problem is described. 


\subsubsection{Input Parameters}

Indices

\begin{tabular}{|l|l|}
\hline Name & Definition \\
\hline$h$ & hour $\{1,2, \ldots, 24\}$ \\
\hline$i$ & technology $\{$ the set of technologies selected $\}$ \\
\hline$p$ & month $\{1,2, \ldots, 12\}$ \\
& $\begin{array}{l}\text { period }\{\text { on-peak, mid-peak, off-peak }\} \text { On-peak (hours of the day } 12 \text { through 18, inclusive, during } \\
\text { through } 06 \text { and } 23 \text { through } 24 \text { during all months })\end{array}$ \\
\hline$s$ & $\begin{array}{l}\text { Season }\{\text { summer, winter }\}: \text { summer (June through September, inclusive) or winter (the remaining } 18 \text { through } 20 \text { during the winter), mid-peak (07 through } 19 \text { through } \\
\text { months })\end{array}$ \\
\hline$u$ & day type $\{$ weekday, peak, weekend $\}$ \\
\hline
\end{tabular}

\section{Customer Data}

\begin{tabular}{|l|l|}
\hline Name & Description \\
\hline Cload $_{m, t, h, u}$ & $\begin{array}{l}\text { Customer load (electricity or heating) in } \mathrm{kW} \text { for end use } u \text { during hour } h \text {, day type } t \text { and month } m \\
\text { (end uses are electricity only, cooling, space heating, and water heating) }\end{array}$ \\
\hline
\end{tabular}

\section{Market Data}

\begin{tabular}{|c|c|}
\hline Name & Description \\
\hline RTPower $_{s, p}$ & $\begin{array}{l}\text { Regulated non-coincident demand charge under the default tariff for season } s \text { and period } p \\
(\mathrm{US} \$ / \mathrm{kW})\end{array}$ \\
\hline RTEnergy $_{m, t, h, u}$ & $\begin{array}{l}\text { Regulated tariff for electricity purchases during hour } h \text {, type of day } t \text {, month } m \text {, and end use } u \\
(\mathrm{US} \$ / \mathrm{kWh})\end{array}$ \\
\hline$R T C D C h \arg e_{m}$ & $\begin{array}{l}\text { Regulated tariff charge for coincident demand, i.e., that occurs at the same time as the monthly } \\
\text { system peak during month } m(\mathrm{US} \$ / \mathrm{kW})\end{array}$ \\
\hline RTCCharge & Regulated tariff customer charge (US\$) \\
\hline
\end{tabular}




\begin{tabular}{|l|l|}
\hline RTFCharge & Regulated tariff facilities charge (US\$/kW) \\
\hline NGBSF $_{m}$ & Natural gas basic service fee for month $m$ (US\$) \\
\hline CTax & Tax on carbon emissions (US\$ $/ \mathrm{kg})$ \\
\hline MktCRate & Carbon emissions rate from marketplace generation $(\mathrm{kg} / \mathrm{kWh})$ \\
\hline NGCRate & Carbon emissions rate from burning natural gas to meet heating and cooling loads (kg/kWh) \\
\hline NatGasPrice ${ }_{m, t, h}$ & Natural gas price during hour $h$, type of day $t$, and month $m(\mathrm{US} \$ / \mathrm{kJ})$ \\
\hline
\end{tabular}

\section{Distributed Energy Resource Technologies Information}

\begin{tabular}{|c|c|}
\hline Name & Description \\
\hline $\operatorname{DERmaxp}_{i}$ & Nameplate power rating of technology $i(\mathrm{~kW})$ \\
\hline DERlifetime $_{i}$ & Expected lifetime of technology $i$ (a) \\
\hline DERcapcost $_{i}$ & Turnkey capital cost of technology $i$ (US\$/kW) \\
\hline DEROMfix & Fixed annual operation and maintenance costs of technology $i(\mathrm{US} \$ / \mathrm{kW})$ \\
\hline DEROMvar & Variable operation and maintenance costs of technology $i(\mathrm{US} \$ / \mathrm{kWh})$ \\
\hline DERhours $_{i}$ & Maximum number of hours technology $i$ is permitted to operate during the year (h) \\
\hline DERCostkWh $h_{i, m}$ & Production cost of technology $i$ during month $m(\mathrm{US} \$ / \mathrm{kWh})$ \\
\hline Annuity $F_{i}$ & Annuity factor for DER technology $i$ \\
\hline CRate $_{i}$ & Carbon emissions rate from technology $i(\mathrm{~kg} / \mathrm{kWh})$ \\
\hline DCCap & Capacity of direct-fired natural gas absorption chiller (AC) (kW) \\
\hline DCPrice & Turnkey cost of direct-fired natural gas AC (US\$) \\
\hline AnnDCPrice & Annualised cost of direct-fired natural gas AC (US\$) \\
\hline DCLifetime & Expected lifetime of direct-fired natural gas AC (a) \\
\hline SHCap & $\begin{array}{l}\text { Capacity of heat storage unit }(\mathrm{kWh}) \text {, which is the maximum total daily heating and cooling } \\
\text { energy use }\end{array}$ \\
\hline SHPrice & Turnkey cost of heat storage unit (US\$) \\
\hline AnnSHPrice & Annualised cost of heat storage unit (US\$) \\
\hline
\end{tabular}




\begin{tabular}{|l|l|}
\hline SHLifetime & Expected lifetime of heat storage unit (a) \\
\hline$S(i)$ & Set of end uses that can be met by technology $i$ \\
\hline
\end{tabular}

\section{Other Parameters}

\begin{tabular}{|c|c|}
\hline Name & Description \\
\hline IntRate & Interest rate on DER investments $(\%)^{3}$ \\
\hline Solar $_{m, h}$ & $\begin{array}{l}\text { Average fraction of maximum solar insolation received (\%) during hour } h \text { and month } m \text { used to } \\
\text { power photovoltaic (PV) cells }{ }^{4}\end{array}$ \\
\hline NGHR & Natural gas heat rate (kJ/kWh) \\
\hline$t(m)$ & Day type in month $m$ when system demand peaks \\
\hline$h(m)$ & Hour in month $m$ when system demand peaks \\
\hline$\alpha_{i}$ & $\begin{array}{l}\text { The amount of heat (in } \mathrm{kW} \text { ) that can be recovered from unit } \mathrm{kW} \text { of electricity that is generated } \\
\text { using DER technology } i \text { (this is equal to } 0 \text { for all technologies that are not equipped with either a } \\
\text { heat exchanger (HX) or an } \mathrm{AC} \text { ) }\end{array}$ \\
\hline$\beta_{u}$ & $\begin{array}{l}\text { The amount of heat (in } \mathrm{kW} \text { ) generated from unit } \mathrm{kW} \text { of natural gas purchased for end use } u \\
\text { (since the electricity-only load never uses natural gas, the corresponding } \beta_{u} \text { value equals } 0 \text { ) }\end{array}$ \\
\hline$\gamma_{i, u}$ & $\begin{array}{l}\text { The amount of useful heat (in } \mathrm{kW} \text { ) that can be allocated to end use } u \text { from unit } \mathrm{kW} \text { of recovered } \\
\text { heat from technology } i \text { (note: since the electricity-only load never uses recovered heat, the } \\
\text { corresponding } \gamma_{i, u} \text { values equal 0) }\end{array}$ \\
\hline$\delta_{u}$ & $\begin{array}{l}\text { The amount of heat (in } \mathrm{kW} \text { ) that can be allocated to end use } u \text { from unit } \mathrm{kW} \text { of stored heat that is } \\
\text { released (note: since the electricity-only load never uses recovered heat, the corresponding } \\
\delta_{u} \text { value equal 0) }\end{array}$ \\
\hline$\varepsilon$ & $\begin{array}{l}\text { The amount of heat (in } \mathrm{kW} \text { ) that is not lost due to dissipation during one hour from unit } \mathrm{kW} \text { of } \\
\text { stored heat }\end{array}$ \\
\hline
\end{tabular}

\footnotetext{
${ }^{3}$ We use an interest rate of $7.5 \%$ per annum in this paper.

${ }^{4}$ We do not consider PV cells in this paper, but have done so in other work (see Siddiqui et al. (2005a) or Siddiqui et al. (2005b), for example). In general, such technologies have high turnkey costs that prevent their adoption unless either the carbon tax is very high or a substantial subsidy is available.
} 


\subsubsection{Decision Variables}

\begin{tabular}{|c|c|}
\hline Name & Description \\
\hline InvGen $_{i}$ & Number of units of technology $i$ installed by the customer \\
\hline$D C$ & Indicator variable for installation of a direct-fired natural gas AC \\
\hline SH & Indicator variable for installation of a heat storage unit \\
\hline $\operatorname{GenL}_{i, m, t, h, u}$ & $\begin{array}{l}\text { Generated power by technology } i \text { during hour } h \text {, type of day } t \text {, month } m \text { and for end use } u \text { to } \\
\text { supply the customer's load }(\mathrm{kW})\end{array}$ \\
\hline $\operatorname{GasP}_{m, t, h, u}$ & Purchased natural gas during hour $h$, type of day $t$, and month $m$ for end use $u(\mathrm{~kW})$ \\
\hline DRLoad $_{m, t, h, u}$ & $\begin{array}{l}\text { Purchased electricity from the distribution company by the customer during hour } h \text {, type of day } t \text {, } \\
\text { and month } m \text { for end use } u(\mathrm{~kW}) \text { (this variable is derived from other variables, but listed here for } \\
\text { clarity) }\end{array}$ \\
\hline RecHeat $_{i, m, t, h, u}$ & $\begin{array}{l}\text { Amount of heat recovered from technology } i \text { that is used to meet end use } u \text { during hour } h \text {, type of } \\
\text { day } t \text {, and month } m(\mathrm{~kW})\end{array}$ \\
\hline StoHeat $_{m, t, h}$ & Amount of stored heat available at the beginning of hour $h$, type of day $t$, and month $m(\mathrm{~kW})$ \\
\hline InHeat $_{i, m, t, h}$ & $\begin{array}{l}\text { Amount of heat from technology } i \text { that is diverted towards the heat storage unit during hour } h \text {, } \\
\text { type of day } t \text {, and month } m(\mathrm{~kW})\end{array}$ \\
\hline OutHeat $_{m, t, h, u}$ & $\begin{array}{l}\text { Amount of stored heat that is released to meet the load of end use } u \text { during hour } h \text {, type of day } t \text {, } \\
\text { and month } m(\mathrm{~kW})\end{array}$ \\
\hline
\end{tabular}

\subsubsection{Problem Formulation}

It is assumed that the site acquires the residual electricity that it needs beyond its selfgeneration from the utility at the regulated tariff. The mathematical formulation of the problem follows: 


$$
\begin{aligned}
& \begin{array}{l}
\text { InvGen }_{i} \\
\text { GenL }_{i, m, t, h, u}
\end{array} \quad \sum_{m} \text { RTFCharge } \cdot \max \left(\sum_{u \in\{\text { electricity-only,cooling }\}} \text { DRLoad }_{m, t, h, u}\right)+\sum_{m} \text { RTCCharge } \\
& \operatorname{GasP}_{m, t, h, u} \\
& \text { RecHeat }_{i, m, t, h, u} \\
& \text { InHeat }_{i, m, t, h} \\
& \text { StoHeat }_{m, t, h} \\
& \text { OutHeat }{ }_{i m, t, h, u} \\
& \text { DC } \\
& \text { SH } \\
& +\sum_{s} \sum_{m \in s} \sum_{p} \text { RTPower }_{s, p} \cdot \max \left(\sum_{u \in\{\text { electricity-only,cooling }\}} \operatorname{DRLoad}_{m,(t, h) \in p, u}\right) \\
& +\sum_{m} \sum_{u \in\{\text { electricity-only,cooling }\}} \text { TCDCharge }_{m} \cdot \text { DRLoad }_{m, t(m), h(m), u}+\text { AnnDCPrice } \cdot D C \\
& + \text { AnnSHPrice } \cdot \text { SH } \\
& +\sum_{m} \sum_{t} \sum_{h} \sum_{u} \text { DRLoad }_{m, t, h, u} \cdot\left(\text { RTEnergy }_{m, t, h}+\text { CTax } \cdot \text { MktCRate }\right) \\
& +\sum_{i} \sum_{m} \sum_{t} \sum_{h} \sum_{u} \operatorname{GenL}_{i, m, t, h, u} \cdot D E R \operatorname{CostkWh} h_{i}+\sum_{i} \sum_{m} \sum_{t} \sum_{h} \sum_{u} \operatorname{GenL}_{i, m, t, h, u} \cdot \text { DEROMvar }_{i} \\
& +\sum_{i} \sum_{m} \sum_{t} \sum_{h} \operatorname{GenL}_{i, m, t, h} \cdot \text { CTax } \cdot \text { CRate }_{i} \\
& +\sum_{i} \operatorname{InvGen}_{i} \cdot \text { DERmaxp }_{i} \cdot\left(\text { DERcapcost }_{i} \cdot \text { AnnuityF }_{i}+\text { DEROMfix }_{i}\right)+\sum_{m} N \text { ABSF }_{m} \\
& +\sum_{m} \sum_{t} \sum_{h} \sum_{u} \text { GasP }_{m, t, h, u} \cdot N G H R \cdot\left(\text { NatGasPrice }_{m, t, h}+\text { CTax } \cdot \text { NGCRate }\right)
\end{aligned}
$$

Subject to:

$$
\operatorname{Cload}_{m, t, h, u}=\sum_{i} \operatorname{GenL}_{i, m, t, h, u}+\operatorname{DRLoad}_{m, t, h, u}+\beta_{u} \cdot \operatorname{GasP}_{m, t, h, u}+\sum_{i}\left(\gamma_{i, u} \cdot \operatorname{RecHeat}_{i, m, t, h, u}\right)+\delta_{u} \cdot \text { OutHeat }_{m, t, h, u} \forall m, t, h, u
$$




$$
\begin{aligned}
& \text { Annuity }_{i}=\frac{\text { IntRate }}{\left(1-\frac{1}{\left(1+\text { IntRate }^{\text {DERlifetime }_{i}}\right.}\right)} \forall i \\
& \sum_{u} \operatorname{GenL}_{i, m, t, h, u} \leq \operatorname{InvGen}_{i} \cdot \operatorname{DER} \max p_{i} \cdot \operatorname{Solar}_{m, h} \forall i, m, t, h \\
& \sum_{m} \sum_{t} \sum_{h} \sum_{u} \operatorname{GenL}_{i, m, t, h, u} \leq \operatorname{InvGen}_{i} \cdot \text { DER max }_{i} \cdot \text { DERhours }_{i} \forall i \\
& \sum_{u} \text { RecHeat }_{i, m, t, h, u}+\text { InHeat }_{i, m, t, h} \leq \alpha_{i} \cdot \sum_{u} \operatorname{GenL}_{i, m, t, h, u} \forall i, m, t, h
\end{aligned}
$$$$
\text { RecHeat }_{i, m, t, h, u}=0 \quad \forall i, m, t, h \quad \text { if } \quad u \notin S(i)
$$

GenL $_{i, m, t, h, u}=0 \quad \forall i, m, t, h \quad$ if $\quad u \in\{$ space heating,water heating $\}$

$\operatorname{GasP}_{m, t, h, u} \leq \mathrm{DCCap} \cdot \mathrm{DC} \quad \forall m, t, h \quad$ if $\quad u \in\{$ cooling $\}$

DRLoad $_{m, t, h, u}=0 \quad \forall m, t, h \quad$ if $\quad u \in\{$ space heating,water heating $\}$

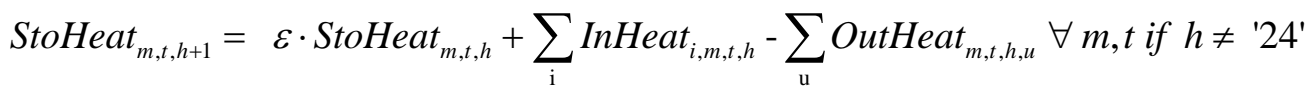

StoHeat $_{m+1, t, 1}=\varepsilon \cdot$ StoHeat $_{m, t, 24}+\sum_{\mathrm{i}}$ InHeat $_{i, m, t, 24}-\sum_{\mathrm{u}}$ OutHeat $_{m, t, 24, u} \forall t$ if $m \neq$ '12' $^{\prime}$

OutHeat $_{m, t, h, u}=0 \quad \forall m, t, h \quad$ if $\quad u \in\{$ electricity only $\}$

StoHeat $_{m, t, h} \leq \mathrm{SHCap} \cdot \mathrm{SH} \quad \forall m, t, h$

StoHeat $_{\{\text {January }\}, t, 1}=0 \forall \mathrm{t}$

StoHeat $_{\{\text {December }\}, t, 24}=0 \forall t$

AnnDC Price $=\frac{\text { IntRate }}{\left(1-\frac{1}{(1+\text { IntRate })^{\text {DCLifetime }}}\right)} \cdot D C$ Price

AnnSH Price $=\frac{\text { IntRate }}{\left(1-\frac{1}{(1+\text { IntRate })^{\text {SHLifetime }}}\right)} \cdot S H$ Pr ice

OutHeat $_{m, t, h, u}=0 \quad \forall u, t \quad$ if $\quad m=$ January' $^{\prime} h=$ ' $^{\prime}$

$\delta_{u} \cdot$ OutHeat $_{m, t, h, u}+\sum_{i} \gamma_{\mathrm{i}, \mathrm{u}} \cdot \operatorname{Re} \mathrm{RHeat}_{i, m, t, h, u} \leq \sum_{i} \alpha_{i} \cdot \gamma_{\mathrm{i}, \mathrm{u}} \cdot \operatorname{InvGen}_{i} \cdot$ DER max $_{i} \quad \forall m, t, h, u$ 


$$
\begin{aligned}
& \sum_{u} \text { OutHeat }_{m, t, h, u} \leq \text { StoHeat }_{m, t, h} \quad \forall m, t, h \\
& \text { SHCap }=\max _{m, t}\left\{\sum_{h} \text { Cload }_{m, t, h, u}\right\} \text { if } u \in\{\text { cooling, space heating, water heating }\}
\end{aligned}
$$

Equation (1) is the objective function that states that the site will try to minimise total energy cost, consisting of facilities and customer charges, monthly demand charges, coincident demand charges, and utility energy charges inclusive of carbon taxation. In addition, the site incurs on-site generation fuel and O\&M costs, carbon taxation on on-site generation, and annualised DER investment costs. Note that the cost of the heat storage unit is set to zero because accurate data on such equipment are not readily available. Instead, we attempt to estimate how much a given $\mathrm{kWh}$ of heat storage capacity is worth to a typical consumer. Finally, for natural gas used to meet heating and cooling loads directly, there are variable and fixed costs (inclusive of carbon taxation).

The constraints to this problem are expressed in equations (2) through (22):

- equation (2) enforces energy balance (it also indicates the means through which the load for energy end use $u$ may be satisfied)

- equation (3) annualises the capital cost of owning on-site generating equipment

- equation (3) annualises the capital cost of owning on-site generating equipment

- equation (4) constrains technology $i$ to generate no more than its installed capacity and in proportion to the solar insolation

- equation (5) places an upper limit on how many hours each type of DER technology can generate during the year ${ }^{5}$

- equation (6) limits how much heat can be recovered for both immediate usage and diversion to storage from each type of DER technology

- equation (7) prevents the use of recovered heat by end uses that cannot be satisfied by the particular DER technology

- equations (8) and (10) are boundary conditions that prevent electricity from being used directly to meet heating loads

- equation (9) prevents direct burning of natural gas to meet the cooling load if no AC for this purpose is purchased

- equation (11) is the heat inventory balance constraint: it states that the total amount of heat stored at the beginning of an hour is equal to the nondissipated heat stored at the beginning of the previous hour plus recovered heat that has been diverted towards storage during that hour minus stored heat that is released to meet end-use loads during that hour ${ }^{6}$

- equation (12) is the same as equation (11), but it is written for the first hour of a month: here, the total heat stored at the beginning of the first hour of a month is equal to the non-dissipated heat stored at the beginning of the last

\footnotetext{
${ }^{5}$ Local air quality regulations may restrict the yearly operating hours of certain technology types.

${ }^{6}$ Since the three day types in this model are simply multiplied by number of such days in each month, there is no overnight storage of heat within a month.
} 
hour of the previous month plus the inflow and minus the outflow of heat during that hour

- equation (13) prevents stored heat from being used by end-use loads such as electricity only

- equation (14) prevents the quantity of heat stored from exceeding the storage capacity

- equation (15) initialises the heat stored to zero

- equation (16) indicates that the stored heat is released at the end of the year

- equations (17) and (18) annualise the turnkey costs of the direct-fired AC and heat storage unit over their respective lifetimes

- equation (19) prevents the use of heat from storage during the first hour of the year

- equation (20) prevents the use of recovered heat from generation or storage for a particular end use unless an appropriate CHP technology is installed ${ }^{7}$

- equation (21) prevents the use of stored heat unless a heat storage unit has been purchased

- equation (22) sets the heat storage capacity to the maximum of the sum of the total daily load of the cooling, space-heating, and water-heating end uses

\section{Data}

For this research, DER-CAM is applied to a cross-section of hypothetical commercial buildings in San Francisco, California, USA. This section describes the data sources of the essential inputs (see Section 2.2.1) to DER-CAM.

\subsection{Load Data}

Data from the 1999 Commercial Buildings Energy Consumption Survey (CBECS, see EIA (2003)) are used to identify the five most common commercial building types:

- mercantile

- lodging

- education

- healthcare

- office

For each building type, a small and large building is modelled. Small buildings have peak electric loads on the order of 300 to $500 \mathrm{~kW}$, the smallest size buildings that typically install DER. Large buildings had peak electric loads in the range of $1-2$ MW, the largest loads typically met by the technologies of primary consideration here: microturbines and reciprocating engines. The set of two building sizes for each of the five building types leads to ten buildings to be modelled in DER-CAM.

The building energy simulation software DOE-2, developed by the Department of Energy (DoE), is used to generate typical energy end-use load data for the ten buildings. The primary task of this software is to supply input information on building hourly loads for DER-CAM.

\footnotetext{
${ }^{7}$ This constraint further implies that the amount of stored heat plus recovered heat to be used in any given hour is limited by the capacity of the HXs installed.
} 


\subsubsection{Method}

Given the selected building types, which are defined based on CBECS, DOE-2 is used to model various building types and determine hourly building energy loads. Based on the output, we then process the data into an hourly data file containing electricity-only, cooling, space-heating, and water-heating loads.

\subsubsection{Building Characteristics}

DOE-2 simulation requires the following input elements:

Building Description

Envelope Characteristics

Operational Characteristics

\section{Equipment Characteristics}

Location, building type, building size, and number of floors

Vintages, construction, insulations, window to wall ratio, window panes and shading coefficient.

Average hot water intensity, peak lighting intensity, peak gas cooking load, and peak electric cooking load. Hours of equipment operation, equipment control strategies, and thermostat set points

Vintage, system types and plant type

Existing research (see Huang et al. (1992)) has categorised thirteen prototype commercial buildings in thirteen regions. Standard building profiles with the aforementioned characteristics were defined, and a large database of hourly load profiles is established through simulation. In this project, five of the most promising building types for DER are chosen, and the standard buildings in the existing research are used to carry out the simulation. The location consists of geographical information, which is obtained from the typical meteorological year (TMY) data sets derived from the 1961-1990 national Solar Radiation Data Base. ${ }^{8}$

\subsubsection{Selection of the Building Size}

Building data are compiled from the CBECS from 1999 to examine the distribution of total commercial floor space among buildings of different sizes, for each of the commercial building types examined in this study. These distributions, along with energy intensity information by building type, are used to determine the presence of buildings in the sizes most conducive to DER. The CBECS data used for this study are in Table 1.

Table 1. The Distribution of Total Commercial Floor Space Among Different Building Sizes (1999 CBECS)

\begin{tabular}{|l|c|c|c|c|c|c|c|c|}
\hline & \multicolumn{7}{|c|}{ Building Size } \\
\hline $\begin{array}{l}\text { Square } \\
\text { Meters } \\
\text { (Thousand }\end{array}$ & $\begin{array}{c}93-465 \\
(1-5)\end{array}$ & $\begin{array}{c}465-930 \\
(5-10)\end{array}$ & $\begin{array}{c}930-2,325 \\
(10-25)\end{array}$ & $\begin{array}{c}2,325-4,650 \\
(25-50)\end{array}$ & $\begin{array}{c}4,650-9,300 \\
(50-100)\end{array}$ & $\begin{array}{c}9,300-18,600 \\
(100-200)\end{array}$ & $\begin{array}{c}18,600-46,500 \\
(200-500)\end{array}$ & $\begin{array}{c}>46,500 \\
(500)\end{array}$ \\
\hline
\end{tabular}

\footnotetext{
${ }^{8}$ The TMY2 data sets were produced by the National Renewable Energy Laboratory's (NREL's) Analytic Studies Division under the Resource Assessment Program, which is funded and monitored by the US DoE’s Office of Solar Energy Conversion.
} 


\begin{tabular}{|c|c|c|c|c|c|c|c|c|}
\hline Square Feet & & & & & & & & \\
\hline & \multicolumn{8}{|c|}{ Total Commercial Floor Space (Million Square Meters) } \\
\hline Health care & 18 & Q & 13 & 25 & 24 & 29 & 70 & 71 \\
\hline Lodging & $\mathrm{Q}$ & 26 & 41 & 106 & 70 & 49 & 74 & $\mathrm{Q}$ \\
\hline Mercantile & 86 & 97 & 198 & 93 & 139 & 164 & 40 & 149 \\
\hline Education & 31 & 41 & 82 & 168 & 199 & 138 & 122 & $\mathrm{Q}$ \\
\hline Office & 113 & 99 & 138 & 111 & 181 & 160 & 145 & 173 \\
\hline
\end{tabular}

$\mathrm{Q}=$ Data withheld because either the relative standard error was greater than $50 \%$ or fewer than twenty buildings were sampled

1 Square Foot $=0.093$ Square Meters

Figure 3 below shows that these CBECS total floor space values (for 1999) accurately compare with the floor-space assumptions in the National Energy Modelling System ${ }^{9}$ (NEMS) for 2004, the lowest year of the current NEMS forecast. As expected, the NEMS floor-space values are slightly higher to account for the growth in commercial floor space between 1999 and 2004. The one exception is the mercantile category, which has much higher total floor space in NEMS than in CBECS. This is because the NEMS Mercantile category also includes Service buildings, while the CBECS does not.

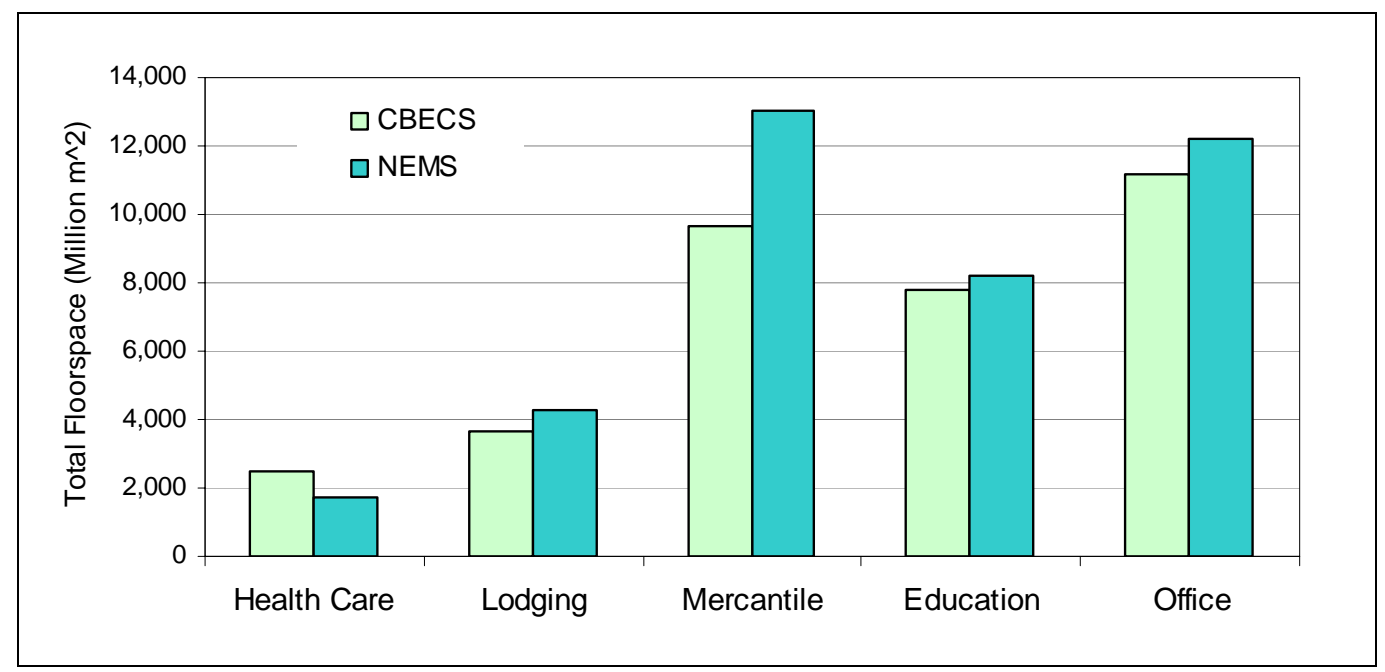

Figure 3. A Comparison of CBECS and NEMS Total Floor-Space Values

For each of these five building types, the peak demand intensity is calculated from DOE-2 simulations (the peak demand intensity is the building peak load in $\mathrm{kW}$ divided by the total building size). This peak demand intensity is then multiplied by the median building size in each of the eight building size categories shown in Table 2. This approximates a total building peak electricity load for each building type, shown with the total corresponding commercial floor space. Table 3 below shows the results of this calculation. By ranking the potential market, peak loads from $300 \mathrm{~kW}$ to $2000 \mathrm{~kW}$ have been selected for the purpose of this project. This is done by using building size ranges that correspond with the minimum and maximum peak load for the DOE-2 simulation as small- and large-sized building.

\footnotetext{
${ }^{9}$ This is a tool developed by the DoE to analyse domestic energy markets by modelling the economics of the supply and demand of energy.
} 
Table 2. Commercial Building Size Distribution Corresponding with Building Peak Load

\begin{tabular}{|c|c|c|c|c|c|c|c|c|}
\hline Building Size $\left(\mathrm{m}^{2}\right)$ & $93-465$ & $465-930$ & $\begin{array}{c}930- \\
2,325\end{array}$ & $\begin{array}{c}2,325- \\
4,650\end{array}$ & $\begin{array}{c}4,650- \\
9,300\end{array}$ & $\begin{array}{l}9,300- \\
18,600\end{array}$ & $\begin{array}{c}18,600- \\
46,500\end{array}$ & $>46,500$ \\
\hline Median Size $\left(\mathrm{m}^{2}\right)$ & 233 & 698 & 1,628 & 3,488 & 6,975 & 13,950 & 32,550 & 60,450 \\
\hline \multicolumn{9}{|l|}{ Peak Loads (kW) } \\
\hline Healthcare & 18.25 & 54.75 & 127.75 & 273.75 & 547.5 & 1095 & 2555 & 4745 \\
\hline Lodging & 7 & 21 & 49 & 105 & 210 & 420 & 980 & 1820 \\
\hline Mercantile & 8.75 & 26.25 & 61.25 & 131.25 & 262.5 & 525 & 1225 & 2275 \\
\hline Education & 11.5 & 34.5 & 80.5 & 172.5 & 345 & 690 & 1610 & 2990 \\
\hline Office & 10.75 & 32.25 & 75.25 & 161.25 & 322.5 & 645 & 1505 & 2795 \\
\hline & & \multirow{4}{*}{\multicolumn{7}{|c|}{$\begin{array}{l}\text { too small (less than } 200 \mathrm{~kW}) \\
\text { slightly too small (200 to } 300 \mathrm{~kW}) \\
\text { worth considering in DER-CAM ( } 300-2000 \mathrm{~kW}) \\
\text { too large to justify using DER-CAM (larger than } 2000 \mathrm{~kW} \text { ) }\end{array}$}} \\
\hline & & & & & & & & \\
\hline & & & & & & & & \\
\hline & & & & & & & & \\
\hline
\end{tabular}

Table 3. Addressed Building Sizes

\begin{tabular}{rcc}
\cline { 2 - 3 } Peak Loads & \multicolumn{2}{c}{ Building Size } \\
Healthcare & $7,200 \mathrm{~m}^{2}$ & Large \\
Lodging & $13,936 \mathrm{~m}^{2}$ & $32,936 \mathrm{~m}^{2}$ \\
Mercantile & $13,936 \mathrm{~m}^{2}$ & $60,387 \mathrm{~m}^{2}$ \\
Education & $7,200 \mathrm{~m}^{2}$ & $32,516 \mathrm{~m}^{2}$ \\
Office & $7,200 \mathrm{~m}^{2}$ & $32,516 \mathrm{~m}^{2}$ \\
\hline
\end{tabular}

\subsubsection{Results}

Table 4 indicates the peak load, total electricity use, total fuel use, and the fuel to electricity $(\mathrm{F} / \mathrm{E})$ ratio of the five buildings in San Francisco. The F/E ratio is highest for the educational building, followed by healthcare and lodging. Examples of hourly load shapes (electricity only, cooling, space heating, and water heating) for a large size healthcare building are shown below (see Figure 4 to Figure 7).

Figure 4 to Figure 7 show the total electricity load and total heating loads in a peak electricity day in January and July each for a healthcare building in San Francisco. It is typical for San Francisco's climate that there is no significant difference between summer and winter in both electricity and natural gas usage. Cooling electricity loads can be observed in the winter, while heating loads occur even in July, although there are differences in the amount of the load. It is attributed to the unique moderate climate throughout the year. The peak electricity-only load is $894 \mathrm{~kW}$ in January and is $892 \mathrm{~kW}$ for July at around time 1100 . The peak cooling load occurs at 1400 with $175 \mathrm{~kW}$ in July and $85 \mathrm{~kW}$ in January.

The space heating for the healthcare building peaks and remains at a high level during the evening and declines during the day. This can be attributed to the thermal gain from more occupants and the higher outdoor temperature during the daytime as the hospital requires more fresh air to keep the indoor air clean and it has occupants at night. Because the clinic zone in the hospital requires $100 \%$ outside air, a HVAC (Heating Ventilation and Air Conditioning) system with variable air exchange was 
applied to keep the air quality, which caused the heating load high at night when the outdoor air temperature is low. The gas load for heating during January weekdays typically ranges from approximately 85 to $1048 \mathrm{MJ}$ with the peak load of $1048 \mathrm{MJ}$ at 0700. There is also significant hot water demand in healthcare buildings. The gas load for hot water ranges from 233 to $1295 \mathrm{MJ}$, with a peak of $1295 \mathrm{MJ}$ also at 0700 .

Table 4. Energy Use of Five Prototype Buildings in San Francisco

\begin{tabular}{|c|c|c|c|c|c|c|c|c|c|c|c|}
\hline & & \multicolumn{2}{|c|}{ Healthcare } & \multicolumn{2}{|c|}{ Lodging } & \multicolumn{2}{|c|}{ Mercantile } & \multicolumn{2}{|c|}{ Education } & \multicolumn{2}{|c|}{ Office } \\
\hline \multicolumn{2}{|c|}{ Building Size } & Small & Large & Small & Large & Small & Large & Small & Large & Small & Large \\
\hline Peak Load & $\mathrm{kW}$ & 539 & 1112 & 383 & 1646 & 498 & 1133 & 304 & 1382 & 338 & 1342 \\
\hline Total Elec & MWh & 3223 & 6597 & 1828 & 7890 & 2293 & 5300 & 559 & 2577 & 1081 & 4457 \\
\hline Total Gas & GJ & 7731 & 12776 & 3151 & 14404 & 278 & 395 & 1959 & 8322 & 1650 & 3707 \\
\hline F/E ratio & MWh/MWh & 0.67 & 0.54 & 0.51 & 0.51 & 0.03 & 0.02 & 0.97 & 0.90 & 0.42 & 0.23 \\
\hline
\end{tabular}

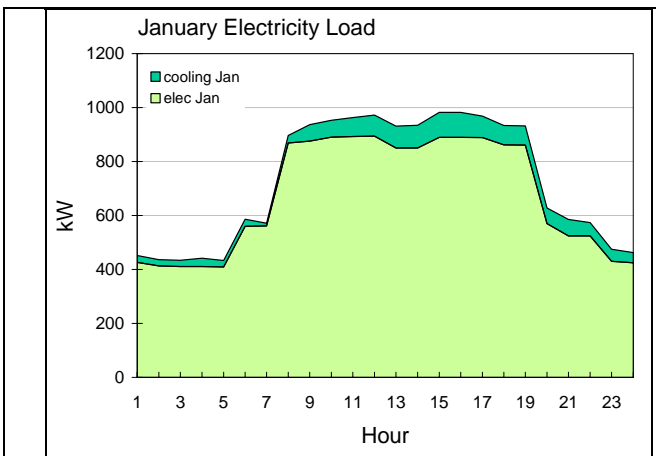

Figure 4. Healthcare January Electricity Load

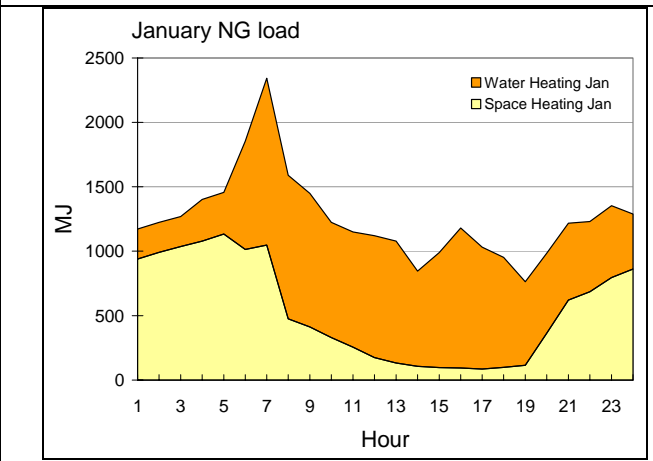

Figure 6. Healthcare January NG Load

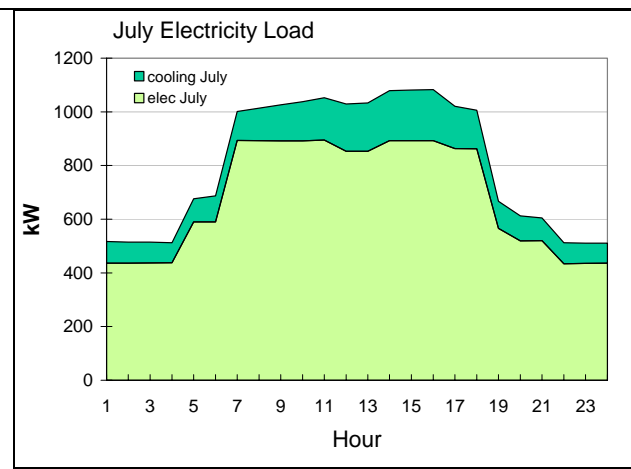

Figure 5. Healthcare July Electricity Load

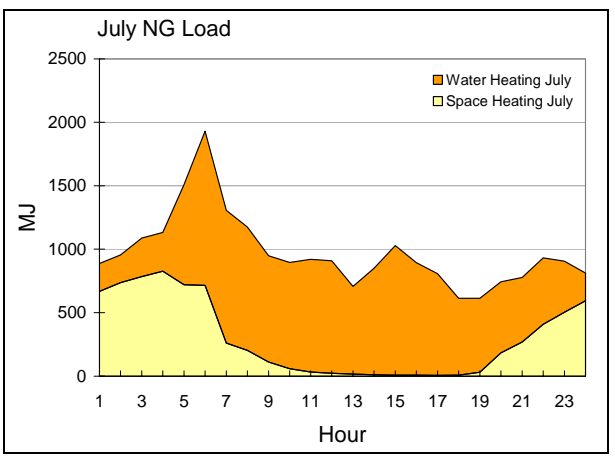

Figure 7. Healthcare July NG Load

\subsection{Tariff Data}

\subsubsection{Electricity}

Utility electricity service is provided to San Francisco by Pacific Gas and Electric (PG\&E); the electricity tariff for San Francisco commercial customers is obtained from the Tariff Analysis Project's database (see LBNL (2005)) of US electricity rates. The three main components of the electricity tariff are volumetric, demand, and fixed fees. Volumetric fees are in proportion to the electricity consumed each month and 
vary with the time of day. Demand fees are in proportion to the maximum rate of electricity consumption during the month, regardless of how often the maximum rate occurs. There are different rates for different times of the day,. The monthly fee is a fixed charge each month. Table 5 summarises these rates.

Table 5. PG\&E Electricity and Power Tariff

\begin{tabular}{|c|c|c|}
\hline Volumetric (\$ & summer* & winter ${ }^{\star *}$ \\
\hline on-peak ${ }^{\star \star \star}$ & 0.16 & 0.11 \\
\hline mid-peak ${ }^{\star \star \star \star}$ & 0.10 & 0.11 \\
\hline off-peak ${ }^{\star \star \star \star \star}$ & 0.09 & 0.09 \\
\hline \multicolumn{3}{|c|}{ Demand (\$/kW) } \\
\hline on-peak ${ }^{\star \star \star}$ & 14.35 & 2.55 \\
\hline mid-peak ${ }^{\star \star \star \star}$ & 5.20 & 5.20 \\
\hline off-peak ${ }^{\star \star \star \star \star}$ & 2.55 & 2.55 \\
\hline \multicolumn{3}{|c|}{ Monthly fee (\$) } \\
\hline & 175.00 & 175.00 \\
\hline
\end{tabular}

*summer months: June-September

**winter months: January-May and October-December

***on-peak hours: summer, $1200-1800$, winter, $1800-2000$

$\star \star \star \star$ mid-peak hours: summer, $0700-1100 \& 1900-2200$, winter, $0700-1700 \& 2100-2200$

$\star \star \star \star \star$ off-peak hours: all months, $0100-0600 \& 2300-2400$

\subsubsection{Natural Gas}

Natural gas rates for San Francisco are obtained from the Annual Energy Outlook 2005 (see EIA (2005)). The rate used is the average commercial rate for the Pacific region. The volumetric cost of natural gas is $\$ 8.89 \times 10^{-6} / \mathrm{kJ}$ for heating applications and DER.

\subsubsection{Carbon Tax}

In addition to the electricity and natural gas tariffs, which reflect the current state of energy costs in San Francisco, a hypothetical carbon tax of US\$100/ton is included.

\subsection{Technology and Thermodynamic Data}

\subsubsection{DG Cost and Performance}

Three natural gas fired DG technology types are considered: microturbines, reciprocating engines, and turbines. Cost and performance data for these technologies are interpolated from data provided in Goldstein et al. (2003), with additional data provided from Firestone (2004). Microturbines and reciprocating engines are considered in two sizes each, and turbines in one size. In DER-CAM, each device can be purchased in one of three packages: 1) as an electricity generation unit, 2) as an electricity generation unit with heat recovery for space and water heating applications, or 3) as an electricity generation unit with heat recovery for space and water heating applications and for cooling via an AC. Cost and performance data for these technologies is summarised in Table 6. The heat to electricity ratio for each unit is 
the $\alpha_{i}$ (see Section 2.2.1). In the cases where heat storage is available, it is assumed to be free. We then try to estimate its economic benefits.

Table 6. DG Technology Data

\begin{tabular}{|c|c|c|c|c|c|c|c|c|}
\hline \multirow[t]{2}{*}{ DG Option } & \multirow[t]{2}{*}{ Lifetime } & \multicolumn{3}{|c|}{ Capital costs } & \multicolumn{2}{|c|}{ Maintanence costs } & \multicolumn{2}{|c|}{ Energy output } \\
\hline & & $\begin{array}{c}\text { electricity } \\
\text { generation } \\
\text { only }\end{array}$ & $\begin{array}{c}\text { with heat } \\
\text { recovery } \\
\text { for } \\
\text { heating }\end{array}$ & $\begin{array}{l}\text { with heat } \\
\text { recovery } \\
\text { for } \\
\text { heating } \\
\text { and } \\
\text { cooling }\end{array}$ & $\begin{array}{c}\text { fixed annual } \\
\text { cost for units } \\
\text { with absorption } \\
\text { chilling }\end{array}$ & variable costs & $\begin{array}{l}\text { electrical } \\
\text { efficiency }\end{array}$ & $\begin{array}{l}\text { heat to } \\
\text { electriciy } \\
\text { ratio }\end{array}$ \\
\hline & (years) & \multicolumn{3}{|c|}{$(\$ / k W$ installed $)$} & $(\$ / k W$ installed $)$ & (\$/kWh generated) & & \\
\hline 1 MW turbine & 20 & 1403 & 1910 & 2137 & 11.9 & 0.010 & 0.219 & 2.45 \\
\hline $100 \mathrm{~kW}$ microturbine & 10 & 1700 & 1980 & 2419 & 17.1 & 0.015 & 0.260 & 2.29 \\
\hline $250 \mathrm{~kW}$ microturbine & 10 & 1400 & 1650 & 1976 & 12.8 & 0.015 & 0.280 & 2.29 \\
\hline $200 \mathrm{~kW}$ reciprocating engine & 20 & 900 & 1225 & 1629 & 15.9 & 0.015 & 0.308 & 1.88 \\
\hline $500 \mathrm{~kW}$ reciprocating engine & 20 & 795 & 1065 & 1339 & 11.0 & 0.012 & 0.332 & 1.55 \\
\hline
\end{tabular}

\subsubsection{Other Technologies}

For this project, HXs used to convert waste heat from DG equipment to useful enduse heat are assumed to be $80 \%$ efficient, as are combustors used to convert natural gas to useful end-use heat. This implies that both the $\beta_{u}$ and $\gamma_{i, u}$ for the space- and water-heating loads are 0.80 (see Section 2.2.1). The coefficient of performance (COP) of electric chillers is assumed to be 5 and that of ACs to be 0.70 . Therefore, the corresponding $\gamma_{i, u}$ (and $\beta_{u}$ if a direct-fired AC is installed) for the cooling load is 0.13 . As for the centralised generation, we assume that it has an efficiency of 0.34 . Furthermore, the fraction of stored heat that can produce useful heat to meet a load, $\delta_{u}$, is also taken to be 0.13 for cooling and 0.80 for the heating loads. Finally, we assume that the fraction of stored heat that is retained from one hour to the next, $\varepsilon$, 0.99 .

\section{Results}

In order to determine the impact of heat storage on costs and operation, we run three DER-CAM cases for each of the ten customer sites in San Francisco:

- No DER: the customer is not allowed to adopt any DER and must meet all electricity and heating loads via off-site purchases of electricity and natural gas

- DER No Heat Storage: the customer may adopt DER (including HXs and ACs), but no heat storage unit

- DER Heat Storage: the customer may adopt DER freely and heat storage units up to a capacity size that is the maximum total daily heating and cooling load

Across these ten sites, we identify the conditions under which heat storage would be economical to adopt. Furthermore, we also gain insight into how stored heat would be used, i.e., whether it would complement or supplement recovered heat. For illustrative purposes, we focus on three customer sites with various relationships between the electricity and heating loads. Finally, we determine the relationship between energy cost savings due to heat storage and the capacity of the heat storage unit. 


\subsection{Low Ratio of Heating to Electricity Loads}

For the small mercantile facility customer site, the heating loads are too small relative to the electricity loads for heat storage to be used. In fact, the cumulative heating loads are only about $2 \%$ of the cumulative electricity loads. As a result, not only is heat storage unattractive, but also HXs and ACs are not adopted. The relationship between the heating and electricity loads is evident from Figure 8 to Figure 11, in which the only heating of significance is for space heating during winter mornings. The installed $500 \mathrm{~kW}$ natural gas reciprocating engine is used to meet most of the electric-only and cooling loads, while the relatively small heating loads are always met by burning natural gas (see Figure 12 and Figure 14 to Figure 17). The energy and financial results indicate that adoption of DER reduces the customer's annual energy bill by $8 \%$ via lower utility purchase of electricity, particularly during on-peak hours (see Table 7 and Table 8).

It is also useful to note that when DER-CAM is run without the heat storage option, the shadow price of equation (14) of the mathematical model (see Section 2.2.3) ${ }^{10}$ is zero for most hours (see Figure 13). This indicates that, ceteris paribus, that there is no value to adopting heat storage. For some of the morning hours, it seems that the shadow price of heat storage capacity is negative, thereby implying that it would be cost-reducing to install a heat storage unit. However, because a HX would be necessary for heat storage to be functional, the negative shadow price is somewhat misleading as the cost of purchasing and installing a HX would be greater than the resulting savings via either heat recovery or storage.

Table 7. Small Mercantile Facility Energy Results

\begin{tabular}{|c|c|c|c|c|c|c|c|c|c|c|}
\hline \multirow{2}{*}{ Case } & \multirow{2}{*}{$\begin{array}{c}\text { Generation } \\
\text { Installed } \\
\end{array}$} & \multirow[t]{2}{*}{ Equipment } & \multicolumn{3}{|c|}{ Annual Utility Purchase } & \multicolumn{5}{|c|}{ Annual DER Production } \\
\hline & & & $\begin{array}{l}\text { Electricity } \\
(M W h)\end{array}$ & $\begin{array}{c}\text { Gas } \\
\text { for } \\
D E R \\
(M W h)\end{array}$ & $\begin{array}{c}\text { Gas } \\
\text { for } \\
\text { direct } \\
\text { end } \\
\text { use } \\
(M W h)\end{array}$ & $\begin{array}{c}\text { Electricity } \\
\text { Loads } \\
\text { (MWh) }\end{array}$ & $\begin{array}{c}\text { Abs } \\
\text { Cool } \\
(M W h)\end{array}$ & $\begin{array}{c}\text { Thermal } \\
\text { Loads } \\
\text { (MWh) }\end{array}$ & $\begin{array}{c}\text { Stored } \\
\text { Heat } \\
\text { for } \\
\text { Cooling } \\
\text { (MWh) }\end{array}$ & $\begin{array}{c}\text { Stored } \\
\text { Heat } \\
\text { for } \\
\text { Heating } \\
\text { (MWh) }\end{array}$ \\
\hline $\begin{array}{l}\text { No } \\
\text { DER }\end{array}$ & & & 2313 & N/A & 60 & N/A & N/A & N/A & N/A & N/A \\
\hline $\begin{array}{l}\text { DER } \\
\text { No } \\
\text { Heat } \\
\text { Storage }\end{array}$ & $500 \mathrm{~kW}$ & $\begin{array}{l}\text { reciprocating } \\
\text { engine }\end{array}$ & 611 & 5126 & 60 & 1702 & 0 & 0 & N/A & N/A \\
\hline $\begin{array}{l}\text { DER } \\
\text { Heat } \\
\text { Storage }\end{array}$ & $500 \mathrm{~kW}$ & $\begin{array}{l}\text { reciprocating } \\
\text { engine }\end{array}$ & 611 & 5126 & 60 & 1702 & 0 & 0 & 0 & 0 \\
\hline
\end{tabular}

\footnotetext{
${ }^{10}$ This dual variable on the heat storage capacity constraint is simply the value of an additional kWh of heat storage capacity (see Nash and Sofer (1996)).
} 
Table 8. Small Mercantile Facility Financial Results

\begin{tabular}{|c|c|c|c|c|c|c|c|c|c|c|}
\hline \multirow[b]{2}{*}{ Case } & \multirow[b]{2}{*}{$\begin{array}{l}\text { Capacity } \\
\text { Installed }\end{array}$} & \multirow[b]{2}{*}{ Equipment } & \multirow{2}{*}{$\begin{array}{c}\text { Investment } \\
\text { Costs } \\
(k U S \$ / a)\end{array}$} & \multicolumn{3}{|c|}{ Annual Utility Bills } & \multirow{2}{*}{$\begin{array}{c}\text { Carbon } \\
\text { Emissions } \\
\text { Cost } \\
(k U S \$) \\
\end{array}$} & \multirow{2}{*}{$\begin{array}{c}\text { Total } \\
\text { Energy } \\
\text { Cost } \\
(\mathrm{kUS} \$)\end{array}$} & \multirow{2}{*}{$\begin{array}{c}\text { Average } \\
\text { Energy } \\
\text { Price } \\
\text { (US\$/kWh) }\end{array}$} & \multirow{2}{*}{$\begin{array}{c}\text { Bill } \\
\text { Savings } \\
\text { Over } \\
\text { No } \\
\text { DER } \\
\text { Case } \\
(\%)\end{array}$} \\
\hline & & & & $\begin{array}{l}\text { Electricity } \\
(k U S \$)\end{array}$ & $\begin{array}{c}\text { Gas } \\
\text { and } \\
\text { O\&M } \\
\text { for } \\
\text { DER } \\
(k U S \$)\end{array}$ & $\begin{array}{c}\text { Gas } \\
\text { for } \\
\text { direct } \\
\text { end } \\
\text { use } \\
(k U S \$)\end{array}$ & & & & \\
\hline $\begin{array}{l}\text { No } \\
\text { DER }\end{array}$ & & & & 326 & N/A & 3 & 22 & 351 & 0.1486 & N/A \\
\hline $\begin{array}{l}\text { DER } \\
\text { No } \\
\text { Heat } \\
\text { Storage }\end{array}$ & $500 \mathrm{~kW}$ & $\begin{array}{l}\text { reciprocating } \\
\text { engine }\end{array}$ & 39 & 65 & 185 & 3 & 31 & 323 & 0.1368 & $8 \%$ \\
\hline $\begin{array}{l}\text { DER } \\
\text { Heat } \\
\text { Storage }\end{array}$ & $500 \mathrm{~kW}$ & $\begin{array}{c}\text { reciprocating } \\
\text { engine }\end{array}$ & 39 & 65 & 185 & 3 & 31 & 323 & 0.1368 & $8 \%$ \\
\hline
\end{tabular}

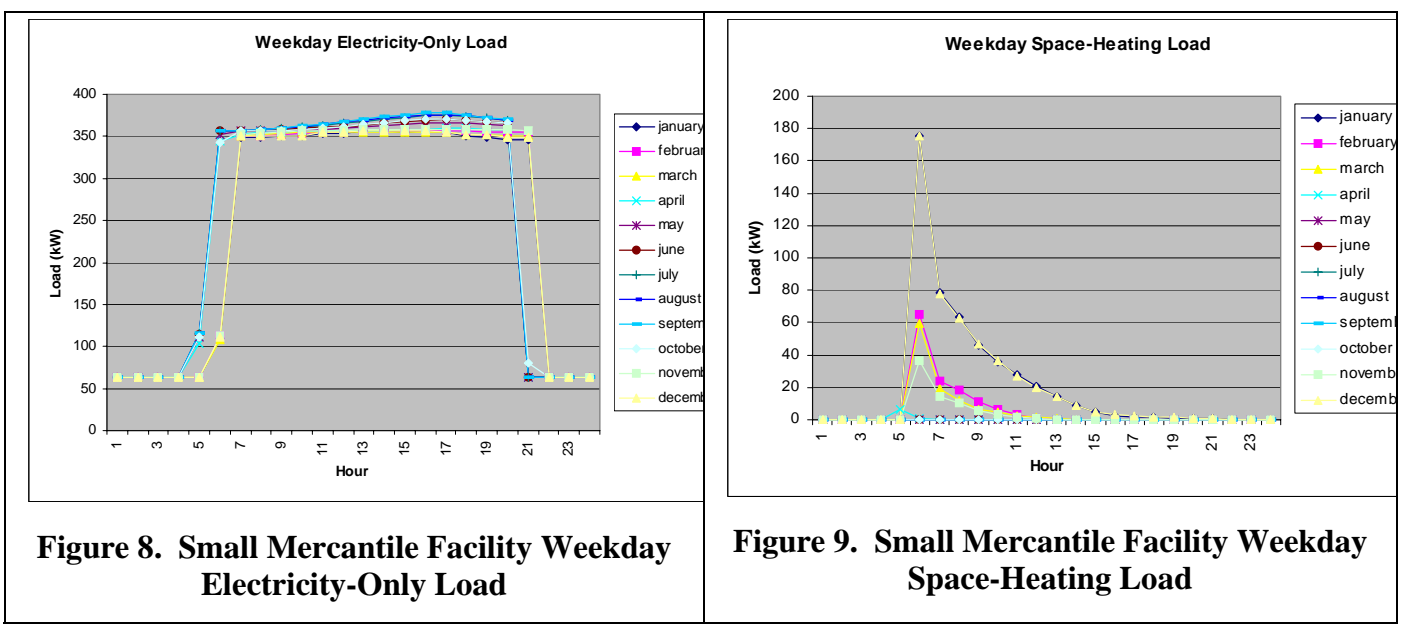

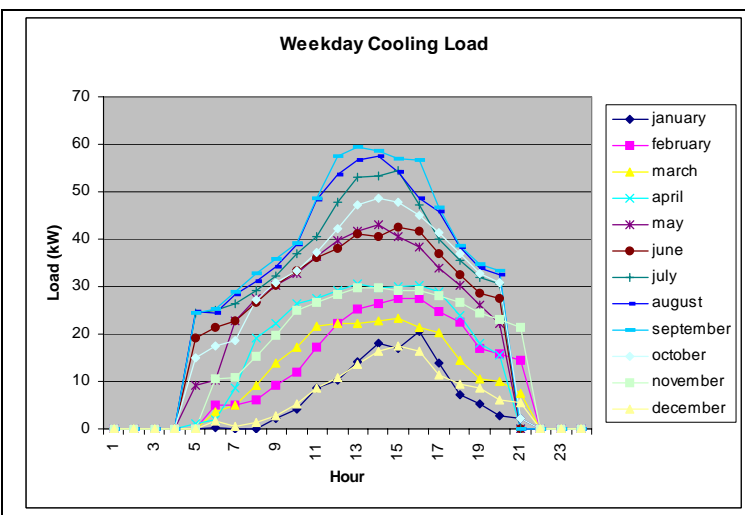

Figure 10. Small Mercantile Facility Weekday Cooling Load

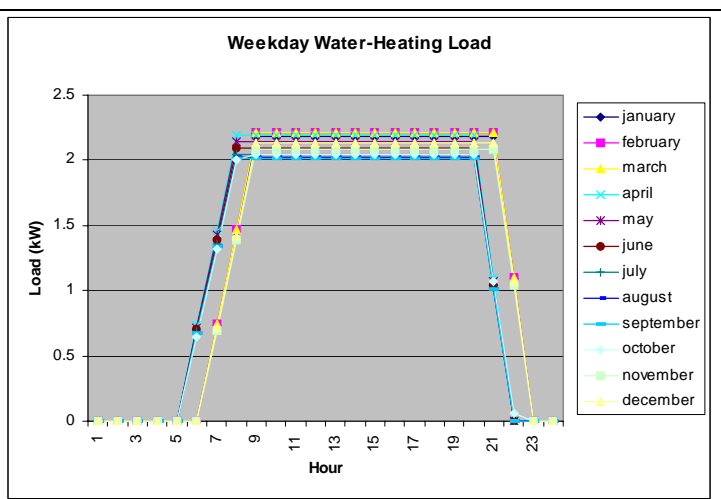

Figure 11. Small Mercantile Facility Weekday Water-Heating Load 


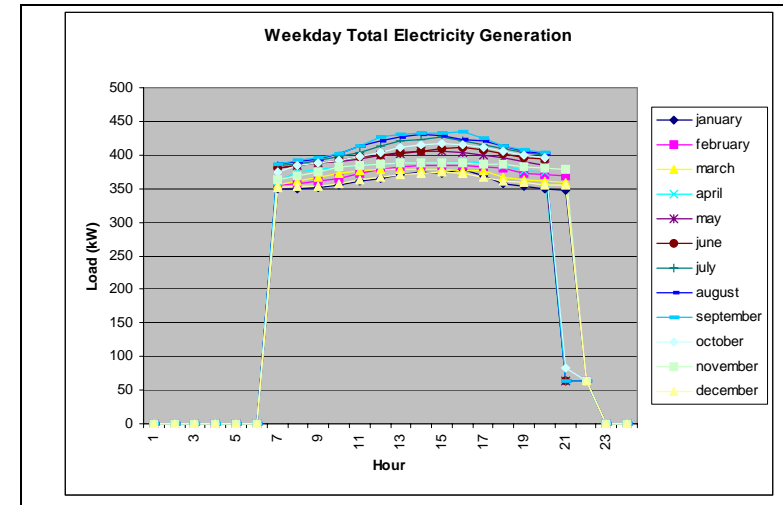

Figure 12. Small Mercantile Facility Weekday Total Electricity Generation

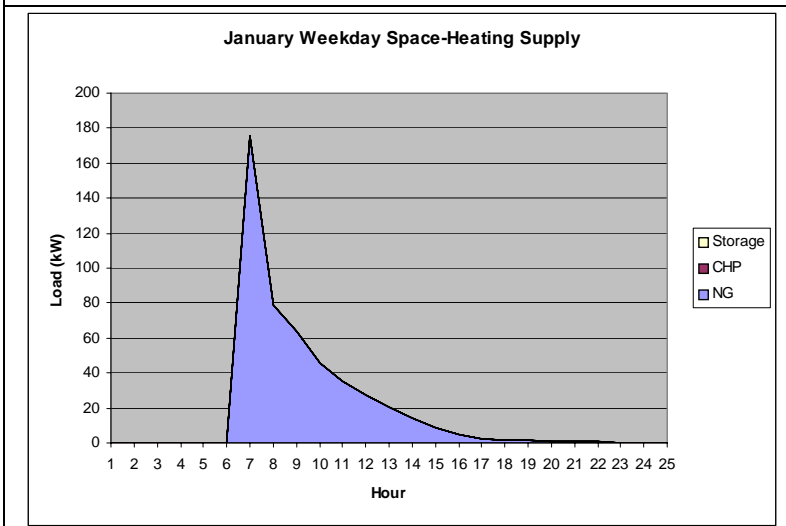

Figure 14. Small Mercantile Facility January Weekday Space-Heating Supply

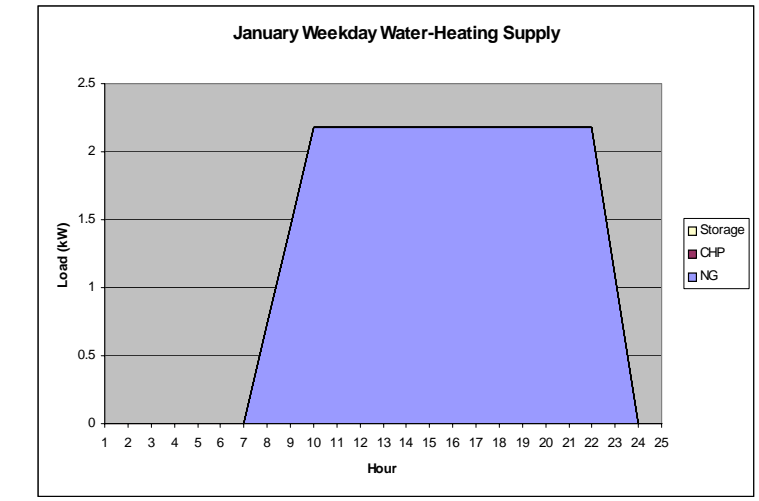

Figure 16. Small Mercantile Facility January Weekday Water-Heating Supply

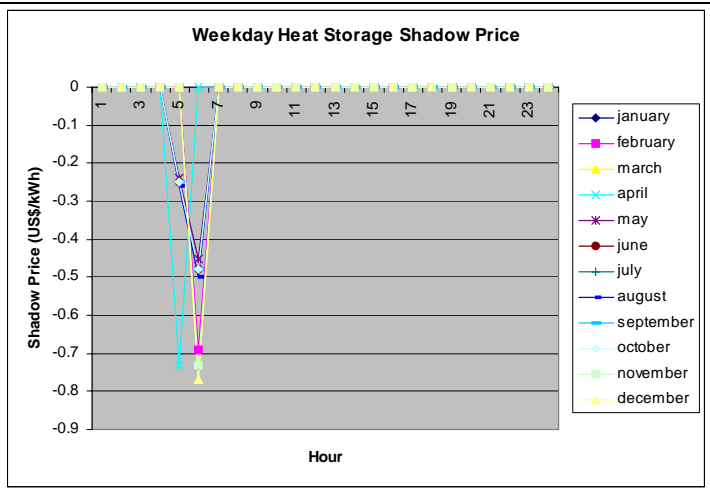

Figure 13. Small Mercantile Facility Weekday Heat Storage Shadow Price

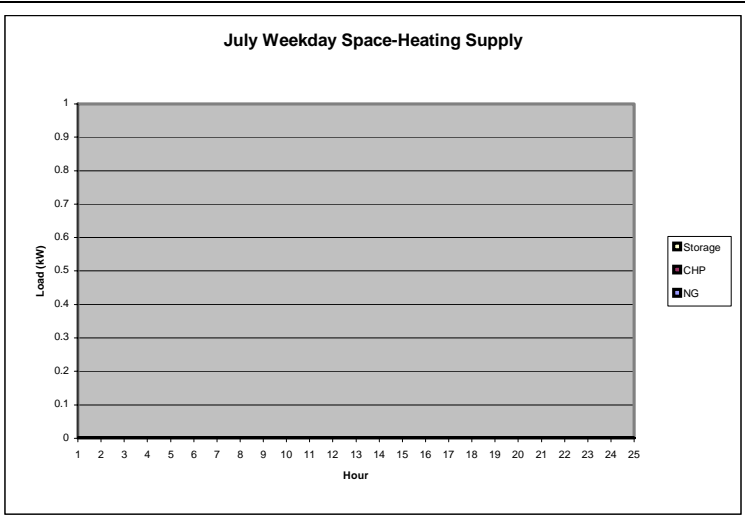

Figure 15. Small Mercantile Facility July Weekday Space-Heating Supply

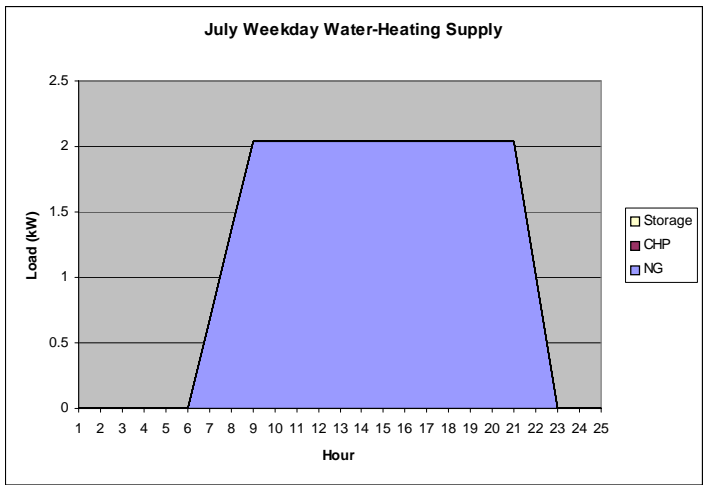

Figure 17. Small Mercantile Facility July Weekday Water-Heating Supply

\subsection{Medium Ratio of Heating to Electricity Loads}

The small lodging facility site has a moderate ratio of cumulative heating to cumulative electricity loads, i.e., around 32\%. More important, however, the heating loads peak at 0800 on January weekdays, precisely when the electricity-only load is 
settling down to its base level and the cooling load is still ramping up (see Figure 18 through Figure 21). In the case with DER, but no heat storage allowed, the site adopts a $200 \mathrm{~kW}$ natural gas reciprocating engine with a bundled HX and AC. This results in most of the electricity-only load being met by on-site generation during on-peak hours and by utility purchases during off-peak hours (see Figure 22). In order to limit the amount of on-peak electricity purchases, the site uses the AC to meet a large fraction, i.e., $60 \%$, of the cooling load with the recovered heat from the on-site electricity generation being almost completely sufficient to meet the heating loads (see Figure 24 and Figure 27).

As the shadow price of heat storage indicates, however, there is substantial potential value to installing a heat storage unit (see Figure 23). This is especially true during the winter mid- and off-peak hours when it is uneconomic to run the on-site generator to cover the electricity-only load and use the recovered heat for the heating loads. Indeed, during such hours, it is cost-effective to use stored heat from the day to meet the heating loads and turn off the generator to rely on relatively cheap utility purchases. Once the adoption of heat storage is allowed, then this is precisely the result as stored heat is used to meet about $30 \%$ of the heating loads and $10 \%$ of the cooling load (see Figure 28 through Figure 32). Furthermore, stored heat is also deployed during some on-peak hours in order to facilitate greater usage of the AC for cooling purposes, either directly or via stored heat. This then reduces the need for onsite generation as more of the cooling load is displaced.

Overall, adoption of DER without the heat storage option reduces the customer's energy bill by $9 \%$ relative to the case in which no DER is allowed. As the free heat storage is made available, a further $1 \%$ cost reduction is attained primarily via less onsite generation of electricity during off-peak hours due to heat storage. To a lesser extent, the elimination of natural gas purchases for meeting heating loads also contributes to this cost saving (see Table 9 and Table 10). Nevertheless, it is ability of the customer to hold an inventory of heat that provides it with the flexibility to rely less on electricity generation. In particular, the total amount of cooling and heating loads that are met on-site (via either recovered or stored heat) increases to $260 \mathrm{MWh}$ and $395 \mathrm{MWh}$, respectively even as on-site generation drops to $928 \mathrm{MWh}$ from 956 MWh. Indeed, by being able to use the heat when it is most valuable, the customer is able to realise additional cost savings. 
Table 9. Small Lodging Facility Energy Results

\begin{tabular}{|c|c|c|c|c|c|c|c|c|c|c|}
\hline \multirow{2}{*}{ Case } & \multirow{2}{*}{$\begin{array}{c}\text { Generation } \\
\text { Installed } \\
\end{array}$} & \multirow[t]{2}{*}{ Equipment } & \multicolumn{3}{|c|}{ Annual Utility Purchase } & \multicolumn{5}{|c|}{ Annual DER Production } \\
\hline & & & $\begin{array}{c}\text { Electricity } \\
(M W h)\end{array}$ & $\begin{array}{c}\text { Gas } \\
\text { for } \\
D E R \\
(M W h)\end{array}$ & $\begin{array}{c}\text { Gas } \\
\text { for } \\
\text { direct } \\
\text { end } \\
\text { use } \\
\text { (MWh) }\end{array}$ & $\begin{array}{c}\text { Electricity } \\
\text { Loads } \\
\text { (MWh) }\end{array}$ & $\begin{array}{c}\text { Abs } \\
\text { Cool }^{11} \\
(M W h)\end{array}$ & $\begin{array}{c}\text { Thermal } \\
\text { Loads } \\
\text { (MWh) }\end{array}$ & $\begin{array}{c}\text { Stored } \\
\text { Heat } \\
\text { for } \\
\text { Cooling } \\
\text { (MWh) }\end{array}$ & $\begin{array}{c}\text { Stored } \\
\text { Heat } \\
\text { for } \\
\text { Heating } \\
\text { (MWh) }\end{array}$ \\
\hline $\begin{array}{l}\text { No } \\
\text { DER }\end{array}$ & & & 1836 & N/A & 494 & N/A & N/A & N/A & N/A & N/A \\
\hline $\begin{array}{l}\text { DER } \\
\text { No } \\
\text { Heat } \\
\text { Storage }\end{array}$ & 200 kW & $\begin{array}{l}\text { reciprocating } \\
\text { engine with } \\
\mathrm{HX} \text { and } \mathrm{AC}\end{array}$ & 732 & 3102 & 2 & 956 & 148 & 394 & N/A & N/A \\
\hline $\begin{array}{l}\text { DER } \\
\text { Heat } \\
\text { Storage }\end{array}$ & $200 \mathrm{~kW}$ & $\begin{array}{l}\text { reciprocating } \\
\text { engine with } \\
\mathrm{HX} \text { and } \mathrm{AC}\end{array}$ & 748 & 3014 & 0 & 928 & 135 & 270 & 25 & 125 \\
\hline
\end{tabular}

Table 10. Small Lodging Facility Financial Results

\begin{tabular}{|c|c|c|c|c|c|c|c|c|c|c|}
\hline \multirow[b]{2}{*}{ Case } & \multirow[b]{2}{*}{$\begin{array}{l}\text { Capacity } \\
\text { Installed }\end{array}$} & \multirow[b]{2}{*}{ Equipment } & \multirow{2}{*}{$\begin{array}{c}\text { Investment } \\
\text { Costs } \\
(k U S \$ / a)\end{array}$} & \multicolumn{3}{|c|}{ Annual Utility Bills } & \multirow{2}{*}{$\begin{array}{c}\text { Carbon } \\
\text { Emissions } \\
\text { Cost } \\
(k U S \$)\end{array}$} & \multirow{2}{*}{$\begin{array}{c}\text { Total } \\
\text { Energy } \\
\text { Cost } \\
(k U S \$)\end{array}$} & \multirow{2}{*}{$\begin{array}{c}\text { Average } \\
\text { Energy } \\
\text { Price } \\
\text { (US\$/kWh) }\end{array}$} & \multirow{2}{*}{$\begin{array}{c}\text { Bill } \\
\text { Savings } \\
\text { Over } \\
\text { No } \\
\text { DER } \\
\text { Case } \\
(\%)\end{array}$} \\
\hline & & & & $\begin{array}{c}\text { Electricity } \\
\text { (kUS\$) }\end{array}$ & $\begin{array}{c}\text { Gas } \\
\text { and } \\
\text { O\&M } \\
\text { for } \\
\text { DER } \\
(k U S \$)\end{array}$ & $\begin{array}{c}\text { Gas } \\
\text { for } \\
\text { direct } \\
\text { end } \\
\text { use } \\
(k U S \$)\end{array}$ & & & & \\
\hline $\begin{array}{l}\text { No } \\
\text { DER }\end{array}$ & & & & 264 & N/A & 19 & 20 & 283 & 0.1269 & N/A \\
\hline $\begin{array}{l}\text { DER } \\
\text { No } \\
\text { Heat } \\
\text { Storage }\end{array}$ & $200 \mathrm{~kW}$ & $\begin{array}{l}\text { reciprocating } \\
\text { engine with } \\
\mathrm{HX} \text { and } \mathrm{AC}\end{array}$ & 35 & 86 & 114 & 1 & 22 & 258 & 0.1155 & $9 \%$ \\
\hline $\begin{array}{l}\text { DER } \\
\text { Heat } \\
\text { Storage }\end{array}$ & $200 \mathrm{~kW}$ & $\begin{array}{l}\text { reciprocating } \\
\text { engine with } \\
\mathrm{HX} \text { and } \mathrm{AC}\end{array}$ & 35 & 87 & 110 & 1 & 22 & 255 & 0.1145 & $10 \%$ \\
\hline
\end{tabular}
11 This is in terms of the MWh of electricity displaced by absorption cooling. The same principle
applies to stored heat used for cooling. 


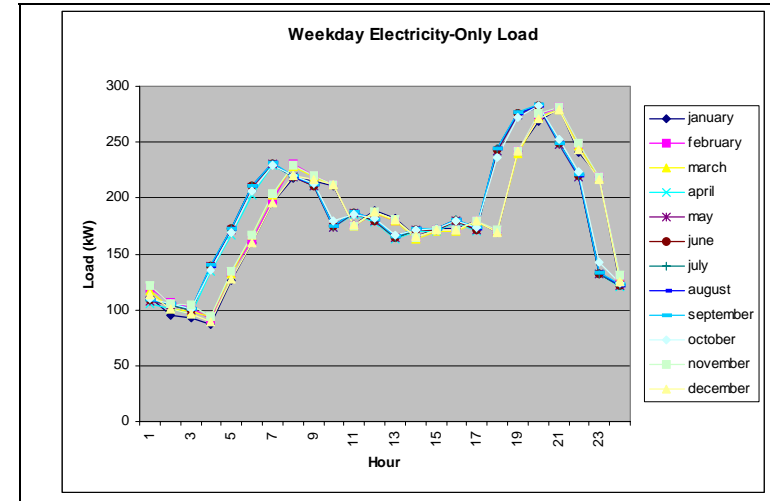

Figure 18. Small Lodging Facility Weekday Electricity-Only Load

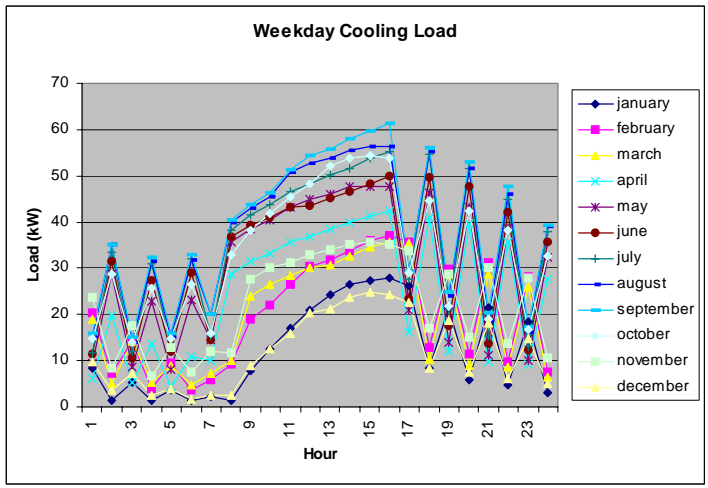

Figure 20. Small Lodging Facility Weekday Cooling Load

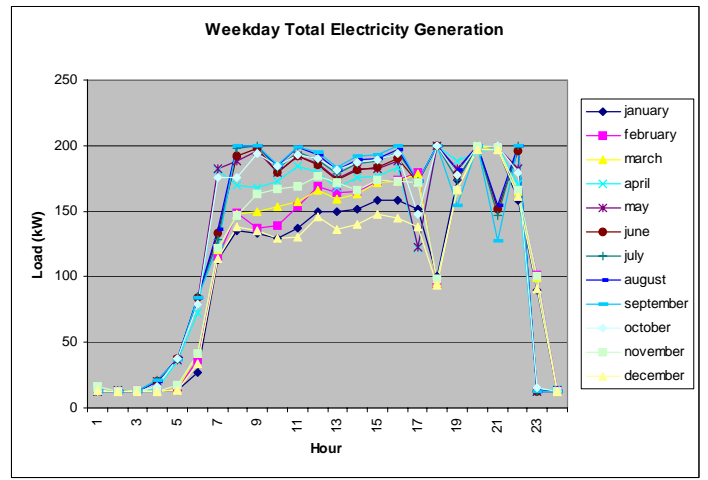

Figure 22. Small Lodging Facility Weekday Total Electricity Generation (No Storage Adoption Allowed)

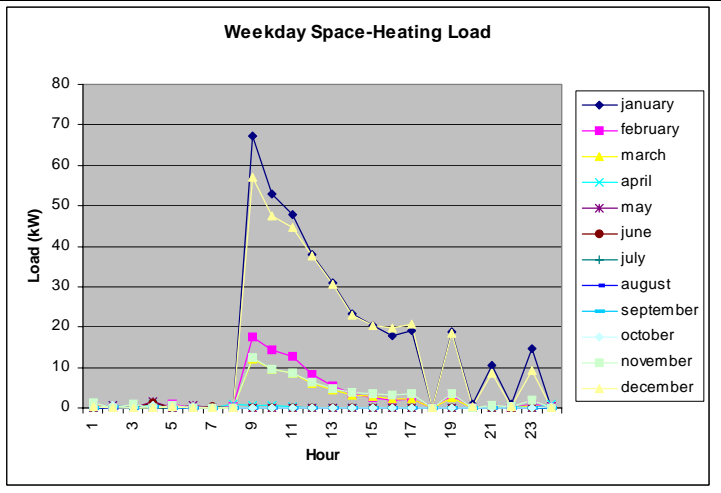

Figure 19. Small Lodging Facility Weekday SpaceHeating Load

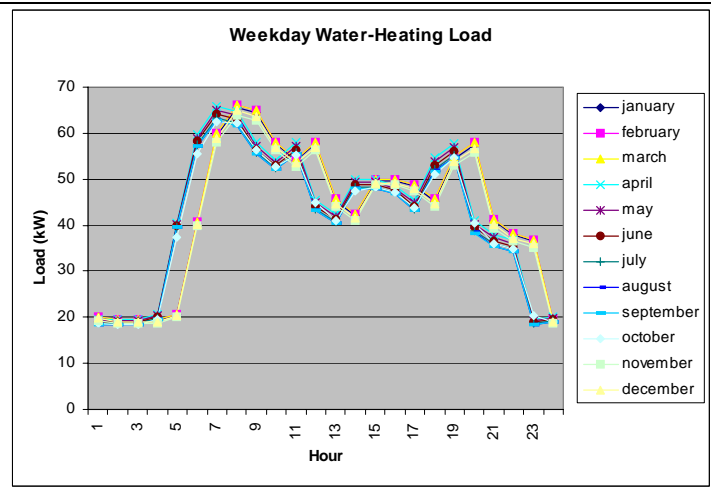

Figure 21. Small Lodging Facility Weekday WaterHeating Load

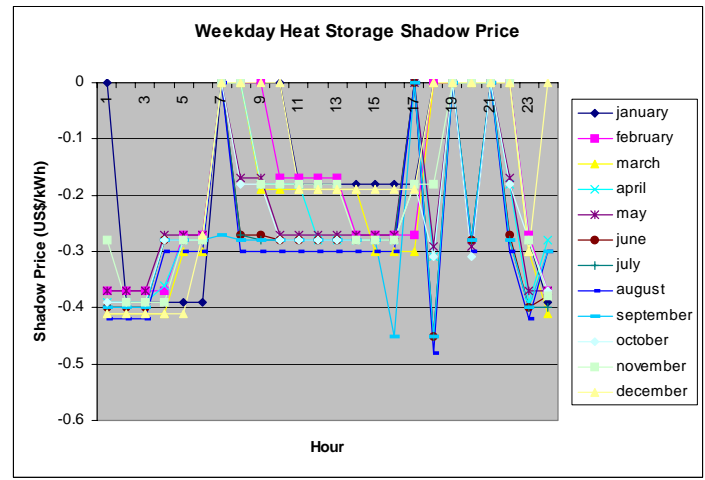

Figure 23. Small Lodging Facility Weekday Heat Storage Shadow Price (No Storage Adoption Allowed) 


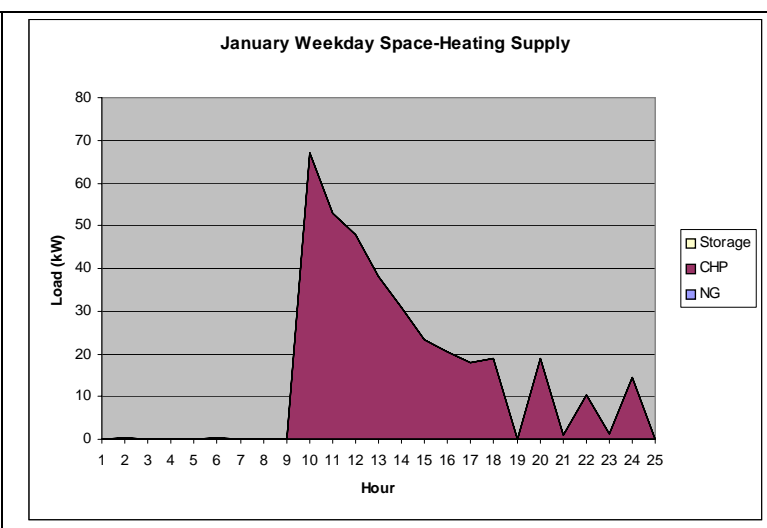

Figure 24. Small Lodging Facility January Weekday Space-Heating Supply (No Storage Adoption Allowed)

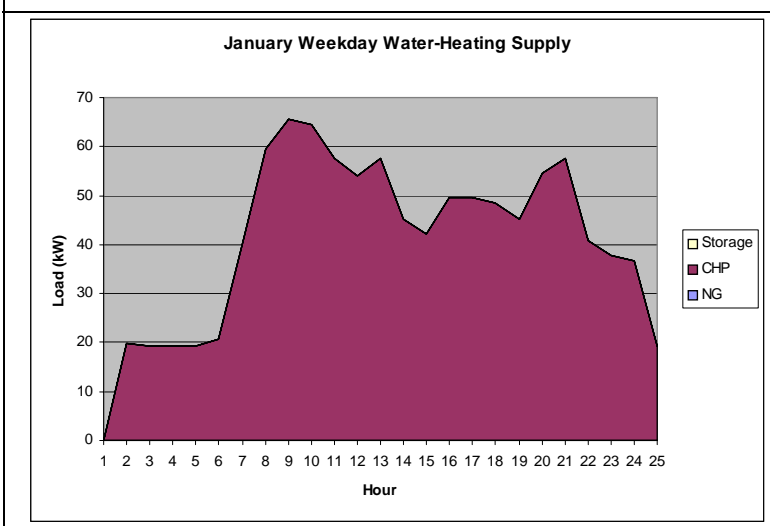

Figure 26. Small Lodging Facility January Weekday Water-Heating Supply (No Storage Adoption Allowed)

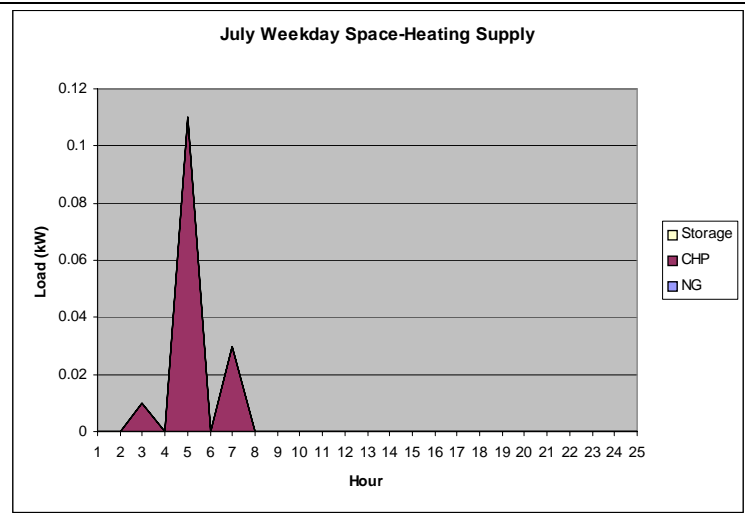

Figure 25. Small Lodging Facility July Weekday Space-Heating Supply (No Storage Adoption Allowed)

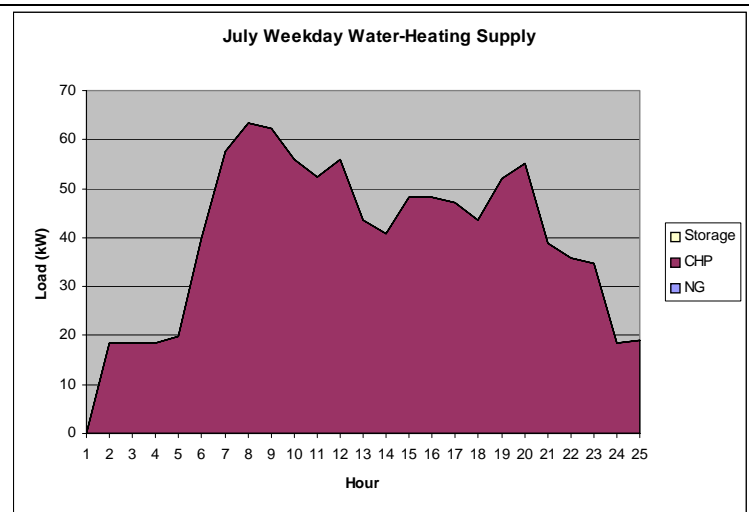

Figure 27. Small Lodging Facility July Weekday Water-Heating Supply (No Storage Adoption Allowed)

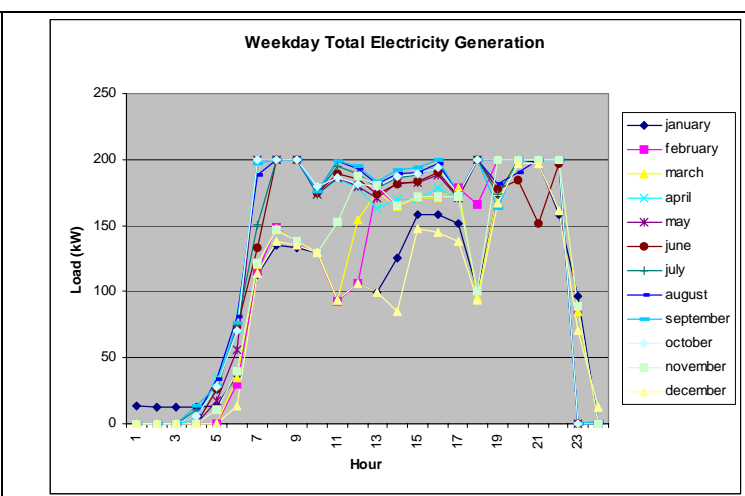

Figure 28. Small Lodging Facility Weekday Total Electricity Generation (Storage Adoption Allowed)

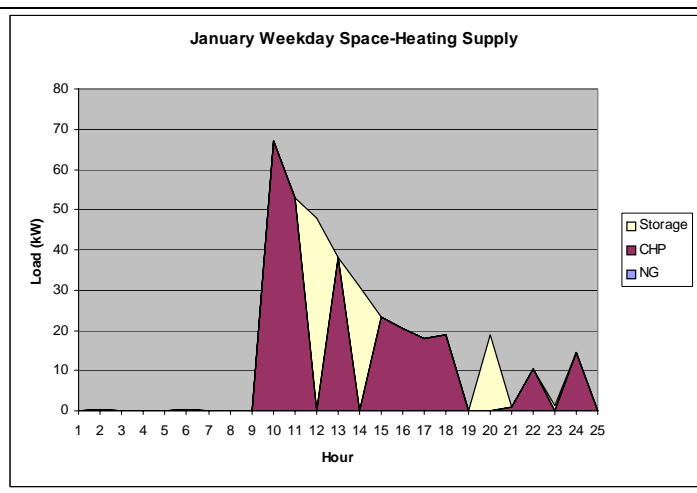

Figure 29. Small Lodging Facility January Weekday Space-Heating Supply (Storage Adoption Allowed) 


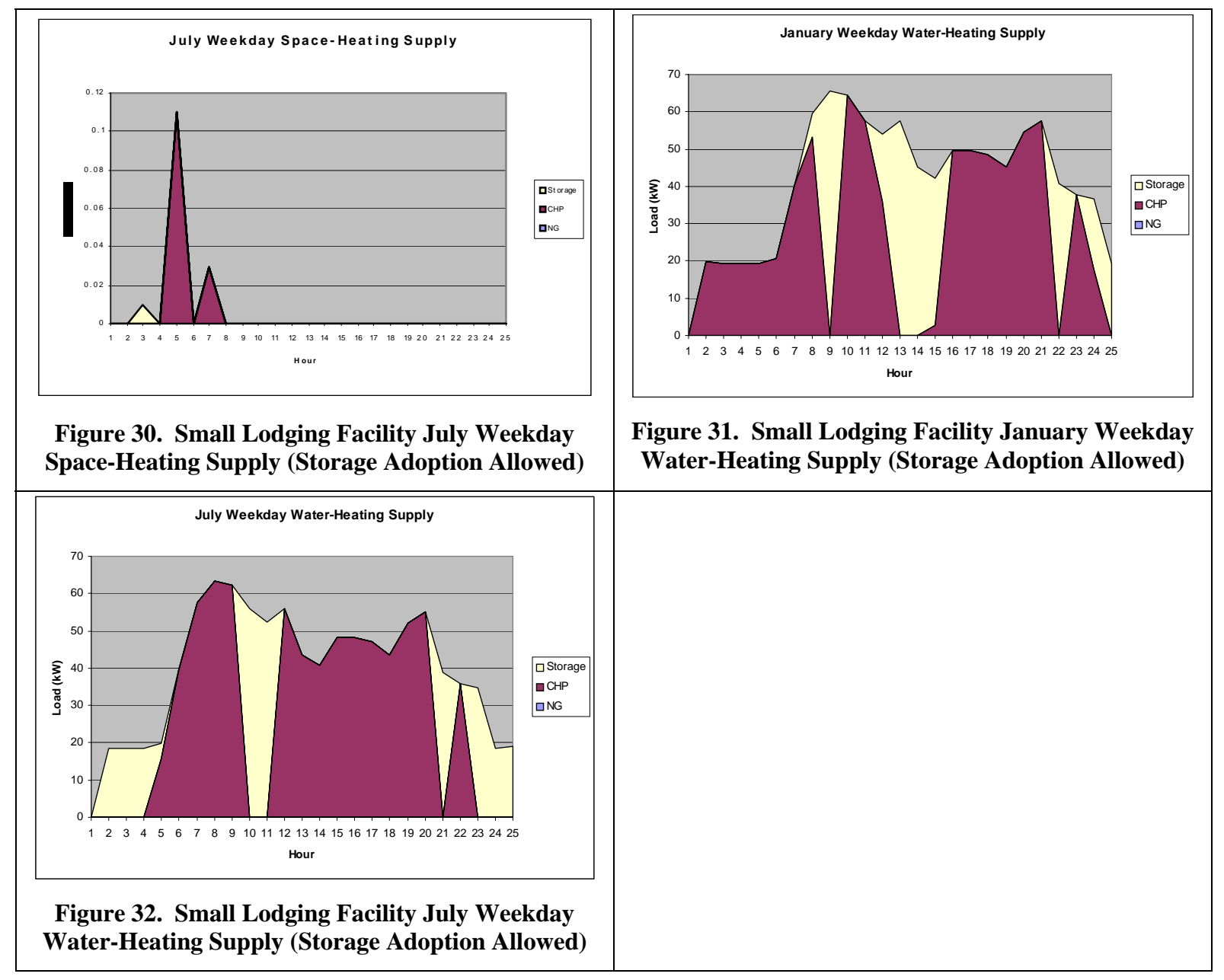

\subsection{High Ratio of Heating to Electricity Loads}

Unlike the small lodging facility, the small educational facility site has a higher ratio (52\%) of cumulative heating to electricity loads. Interestingly, the space-heating load peak occurs at 0700 in December and is non-coincident with the electricity loads. By contrast, the water-heating load peaks at 1400 and is coincident with both electricity loads (see Figure 33 through Figure 36). In the case with DER allowed but no heat storage, a $200 \mathrm{~kW}$ natural gas reciprocating engine with a $\mathrm{HX}$ is installed. Since no $\mathrm{AC}$ is installed, on-site electricity generation is crucial in meeting most of the on-peak electricity-only and cooling loads. In effect, $76 \%$ of the electricity-only and $68 \%$ of the cooling loads are met via on-site generation (see Figure 37). The resulting heat that is recovered from this generation is then used to meet $92 \%$ of the space-heating load and $100 \%$ of the water-heating load (see Figure 39 and Figure 42).

Using the shadow price on the heat storage constraint, we determine that the value of heat storage is relatively high during the morning mid- and off-peak hours (see Figure 38). This is because there is a moderately high space-heating load, but a very low electricity load (including cooling needs). Consequently, the site operates its on-site generator to meet the electricity load simply to obtain some recovered heat even though off-peak utility purchases would be more economical. It is constrained to such 
a policy because it wishes to reduce its bill for burning natural gas to meet the spaceheating load.

When adoption of the free heat storage unit is permitted, the customer site optimally uses it to store heat during winter mornings and deploys it to meet the space- and water-heating loads (see Figure 44 through Figure 47). The availability of this resource also implies that the facility can reduce its on-site electricity generation during off-peak hours (see Figure 43). Overall with heat storage, about $74 \%$ of the electricity-only and 54\% of the cooling loads are met via on-site generation, a reduction from the case in which no heat storage is allowed. The increased costs resulting from higher mid- and off-peak utility purchases are more than offset by lower electricity costs from on-site generation (see Table 11 and Table 12). On top of this, the use of heat storage allows $57 \%$ of the space-heating load and $66 \%$ of the water-heating load to be met via on-site means, thereby lowering costs even further for the facility. While most of this occurs during mid- and off-peak hours (in the case of the space-heating load), some amount is also deployed during on-peak hours for the water-heating load as heat stored from the morning and early afternoon is used.

While the installation of DER alone (without heat storage) is able to lower the customer's overall energy bill by 7\%, it still requires purchase of $24 \mathrm{MWh}$ of natural gas each year to meet the heating loads directly. The use of inventory enabled by the heat storage unit lowers the energy bill by another $1 \%$ per year by significantly reducing the amount of natural gas purchased for direct end usage. As a result, the overall annual amount of heating loads met on-site increases to 304 MWh from 291 MWh. Effectively, the customer purchases more electricity from the utility during mid- and off-peak hours, a cost increase that is more than offset by the savings from less on-site generation and fewer purchases of natural gas for direct end usage. Hence, unlike the small lodging facility, the small educational facility saves as much from lower electricity costs as it does from lower natural gas costs.

Table 11. Small Educational Facility Energy Results

\begin{tabular}{|c|c|c|c|c|c|c|c|c|c|c|}
\hline \multirow{2}{*}{ Case } & \multirow{2}{*}{$\begin{array}{c}\text { Generation } \\
\text { Installed }\end{array}$} & \multirow[t]{2}{*}{ Equipment } & \multicolumn{3}{|c|}{ Annual Utility Purchase } & \multicolumn{5}{|c|}{ Annual DER Production } \\
\hline & & & $\begin{array}{c}\text { Electricity } \\
(M W h)\end{array}$ & $\begin{array}{c}\text { Gas } \\
\text { for } \\
D E R \\
(M W h)\end{array}$ & $\begin{array}{c}\text { Gas } \\
\text { for } \\
\text { direct } \\
\text { end } \\
\text { use } \\
(M W h)\end{array}$ & $\begin{array}{l}\text { Electricity } \\
\text { Loads } \\
(M W h)\end{array}$ & $\begin{array}{c}\text { Abs } \\
\text { Cool } \\
(M W h)\end{array}$ & $\begin{array}{c}\text { Thermal } \\
\text { Loads } \\
\text { (MWh) }\end{array}$ & $\begin{array}{c}\text { Stored } \\
\text { Heat } \\
\text { for } \\
\text { Cooling } \\
\text { (MWh) }\end{array}$ & $\begin{array}{l}\text { Stored } \\
\text { Heat } \\
\text { for } \\
\text { Heating } \\
(M W h)\end{array}$ \\
\hline $\begin{array}{l}\text { No } \\
\text { DER }\end{array}$ & & & 601 & N/A & 387 & N/A & N/A & N/A & N/A & N/A \\
\hline $\begin{array}{l}\text { DER } \\
\text { No } \\
\text { Heat } \\
\text { Storage }\end{array}$ & $200 \mathrm{~kW}$ & $\begin{array}{c}\text { reciprocating } \\
\text { engine with } \\
\text { HX }\end{array}$ & 150 & 1464 & 24 & 451 & 0 & 291 & N/A & N/A \\
\hline $\begin{array}{l}\text { DER } \\
\text { Heat } \\
\text { Storage }\end{array}$ & $200 \mathrm{~kW}$ & $\begin{array}{c}\text { reciprocating } \\
\text { engine with } \\
\text { HX }\end{array}$ & 170 & 1397 & 7 & 430 & 0 & 119 & 0 & 185 \\
\hline
\end{tabular}


Table 12. Small Educational Facility Financial Results

\begin{tabular}{|c|c|c|c|c|c|c|c|c|c|c|}
\hline \multirow[b]{2}{*}{ Case } & \multirow[b]{2}{*}{$\begin{array}{l}\text { Capacity } \\
\text { Installed }\end{array}$} & \multirow[b]{2}{*}{ Equipment } & \multirow{2}{*}{$\begin{array}{c}\text { Investment } \\
\text { Costs } \\
(k U S \$ / a)\end{array}$} & \multicolumn{3}{|c|}{ Annual Utility Bills } & \multirow{2}{*}{$\begin{array}{c}\text { Carbon } \\
\text { Emissions } \\
\text { Cost } \\
(k U S \$) \\
\end{array}$} & \multirow{2}{*}{$\begin{array}{c}\text { Total } \\
\text { Energy } \\
\text { Cost } \\
(k U S \$)\end{array}$} & \multirow{2}{*}{$\begin{array}{c}\text { Average } \\
\text { Energy } \\
\text { Price } \\
\text { (US\$/kWh) }\end{array}$} & \multirow{2}{*}{$\begin{array}{c}\text { Bill } \\
\text { Savings } \\
\text { Over } \\
\text { No } \\
\text { DER } \\
\text { Case } \\
(\%)\end{array}$} \\
\hline & & & & $\begin{array}{c}\text { Electricity } \\
(k U S \$)\end{array}$ & $\begin{array}{c}\text { Gas } \\
\text { and } \\
\text { O\&M } \\
\text { for } \\
\text { DER } \\
(k U S \$)\end{array}$ & $\begin{array}{c}\text { Gas } \\
\text { for } \\
\text { direct } \\
\text { end } \\
\text { use } \\
\text { (kUS\$) }\end{array}$ & & & & \\
\hline $\begin{array}{l}\text { No } \\
\text { DER }\end{array}$ & & & & 96 & N/A & 14 & 7 & 117 & 0.1290 & N/A \\
\hline $\begin{array}{l}\text { DER } \\
\text { No } \\
\text { Heat } \\
\text { Storage }\end{array}$ & $200 \mathrm{~kW}$ & $\begin{array}{c}\text { reciprocating } \\
\text { engine with } \\
\text { HX }\end{array}$ & 24 & 21 & 54 & 2 & 9 & 110 & 0.1205 & $7 \%$ \\
\hline $\begin{array}{l}\text { DER } \\
\text { Heat } \\
\text { Storage }\end{array}$ & $200 \mathrm{~kW}$ & $\begin{array}{c}\text { reciprocating } \\
\text { engine with } \\
\text { HX }\end{array}$ & 24 & 23 & 51 & 1 & 9 & 108 & 0.1192 & $8 \%$ \\
\hline
\end{tabular}

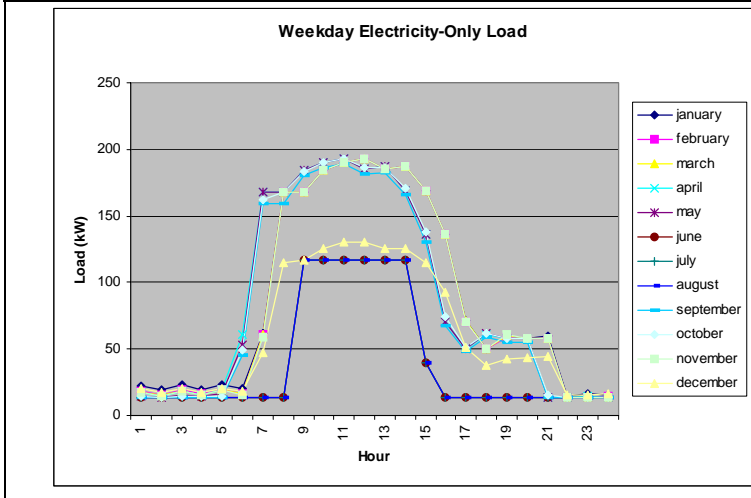

Figure 33. Small Educational Facility Weekday Electricity-Only Load

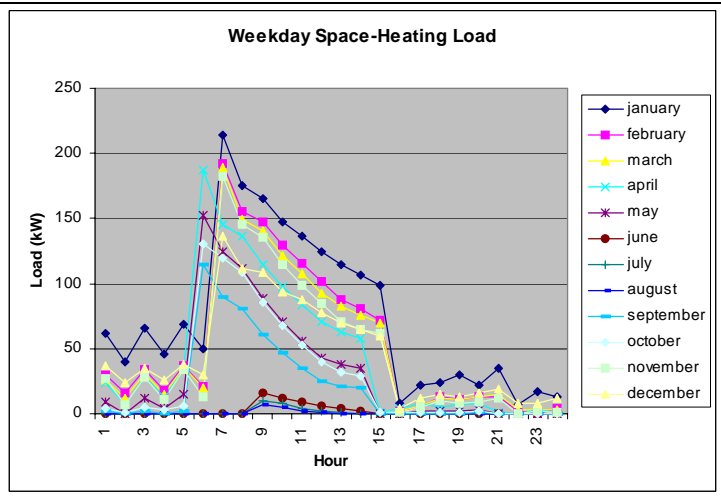

Figure 34. Small Educational Facility Weekday Space-Heating Load 


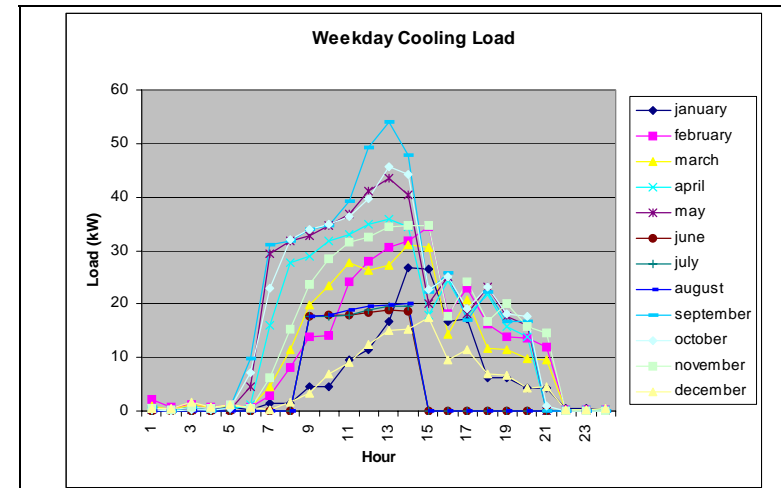

Figure 35. Small Educational Facility Weekday Cooling Load

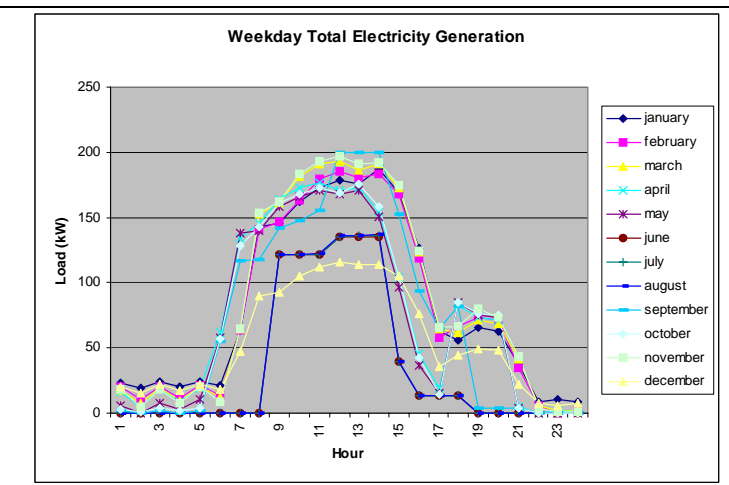

Figure 37. Small Educational Facility Weekday Total Electricity Generation (No Storage Adoption Allowed)

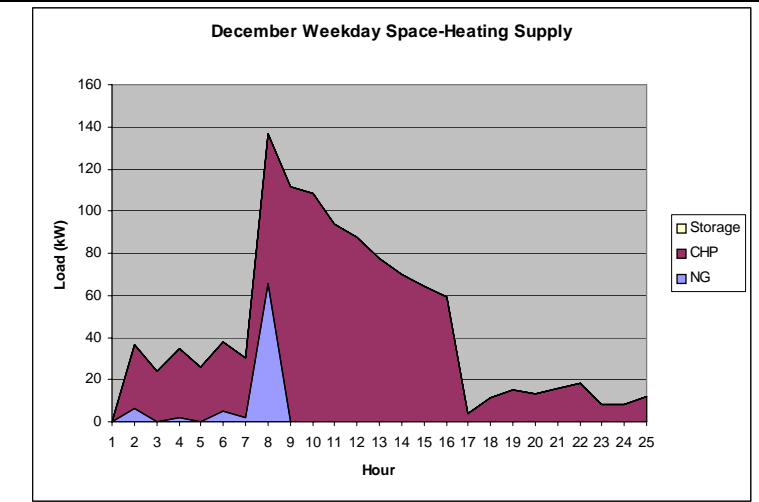

Figure 39. Small Educational Facility December Weekday Space-Heating Supply (No Storage Adoption Allowed)

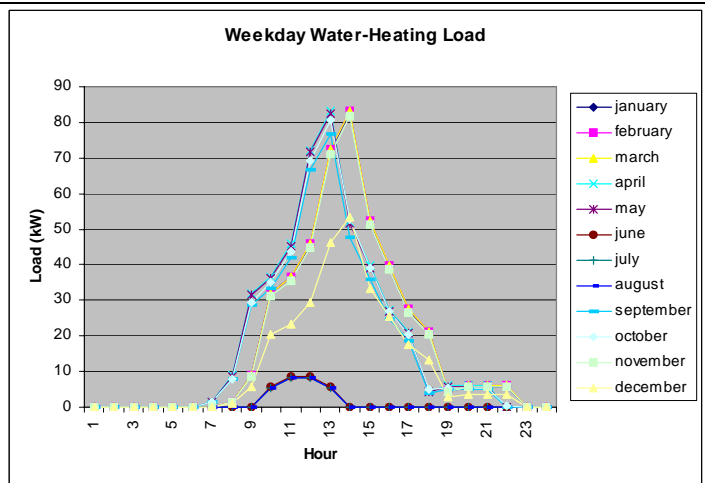

Figure 36. Small Educational Facility Weekday Water-Heating Load

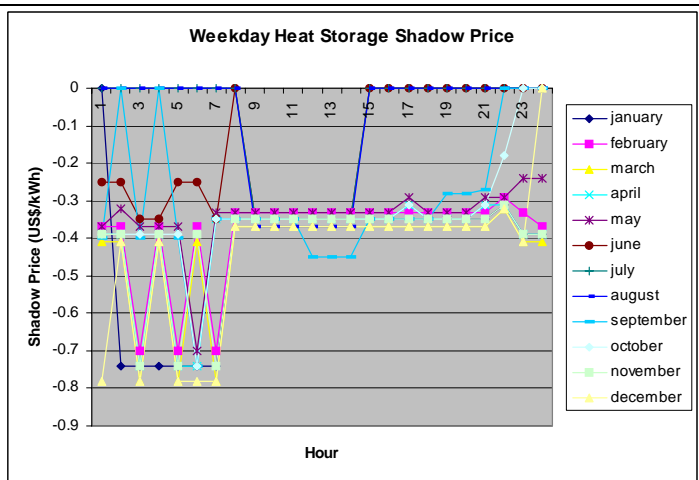

Figure 38. Small Educational Facility Weekday Heat Storage Shadow Price (No Storage Adoption Allowed)

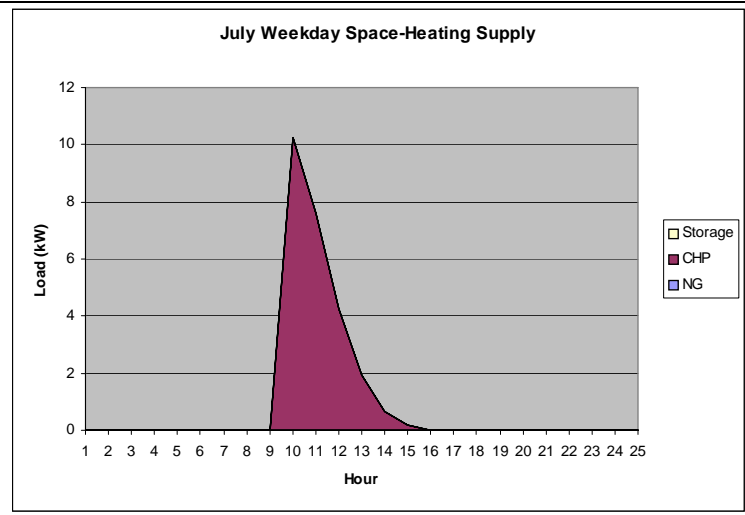

Figure 40. Small Educational Facility July Weekday Space-Heating Supply (No Storage Adoption Allowed) 


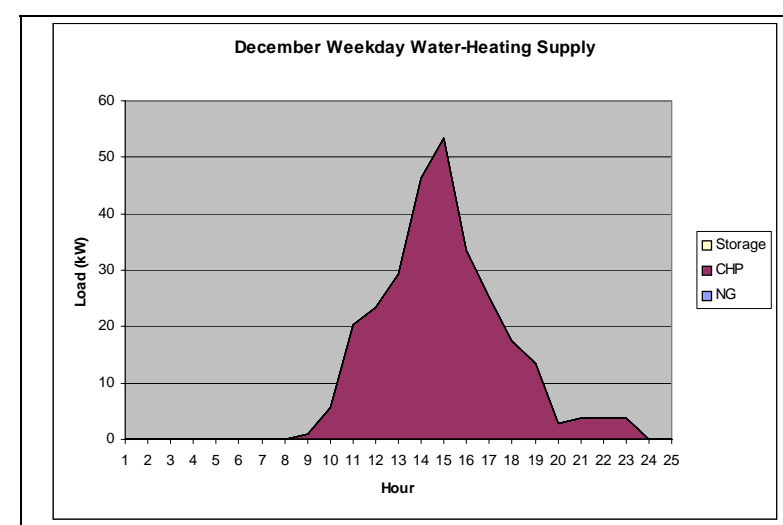

Figure 41. Small Educational Facility December Weekday Water-Heating Supply (No Storage Adoption Allowed)

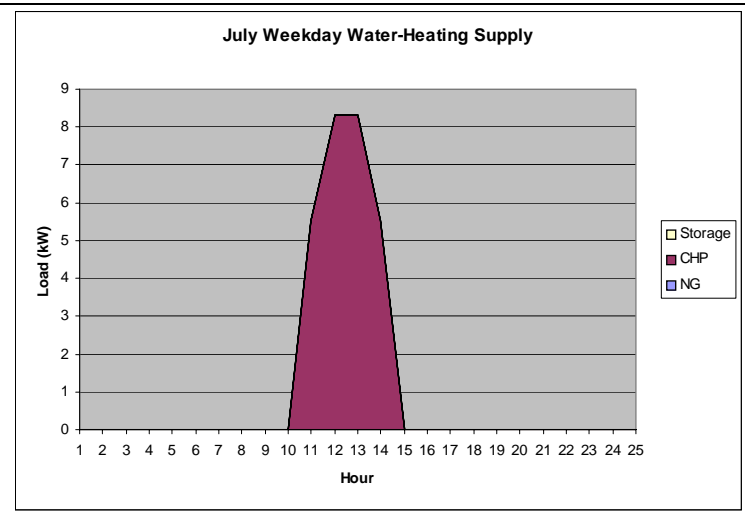

Figure 42. Small Educational Facility July Weekday Water-Heating Supply (No Storage Adoption Allowed)

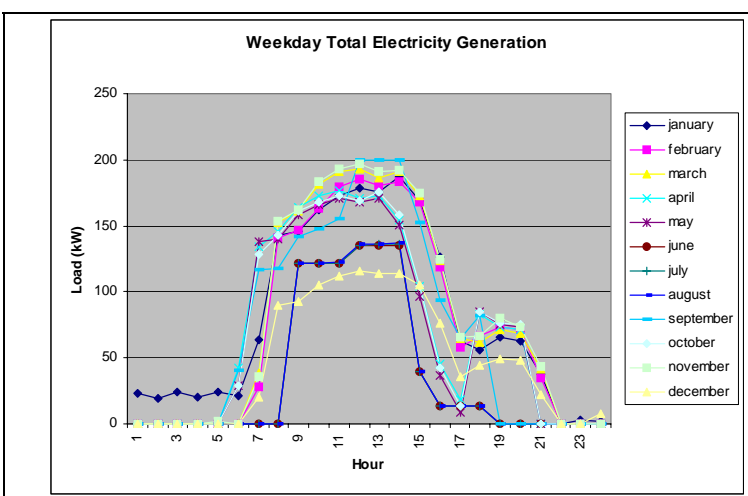

Figure 43. Small Educational Facility Weekday Total Electricity Generation (Storage Adoption Allowed)

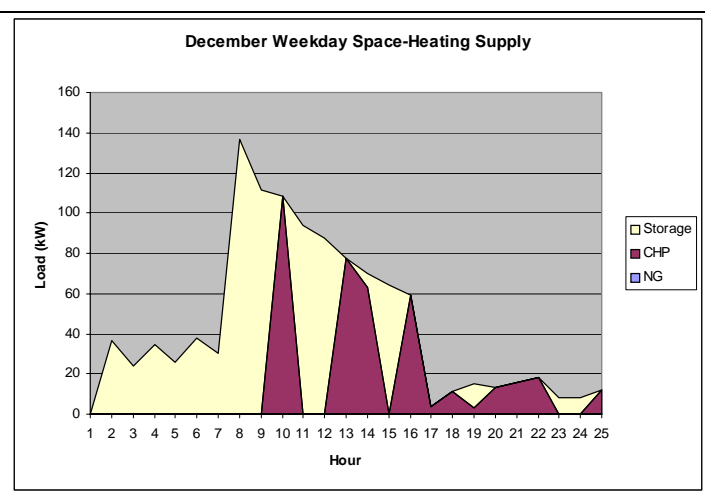

Figure 44. Small Educational Facility December Weekday Space-Heating Supply (Storage Adoption Allowed)

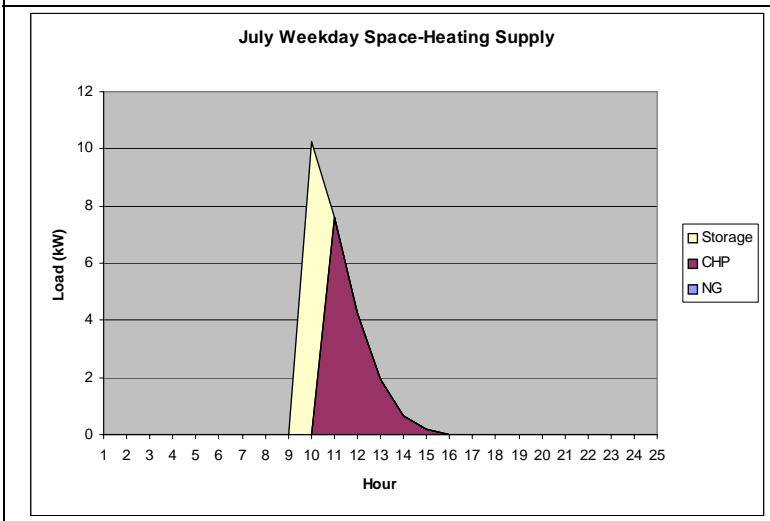

Figure 45. Small Educational Facility July Weekday Space-Heating Supply (Storage Adoption Allowed)

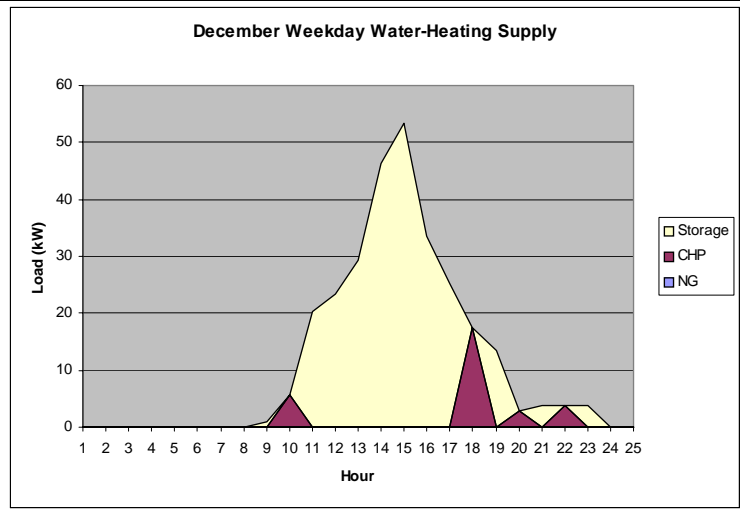

Figure 46. Small Educational Facility December Weekday Water-Heating Supply (Storage Adoption Allowed) 


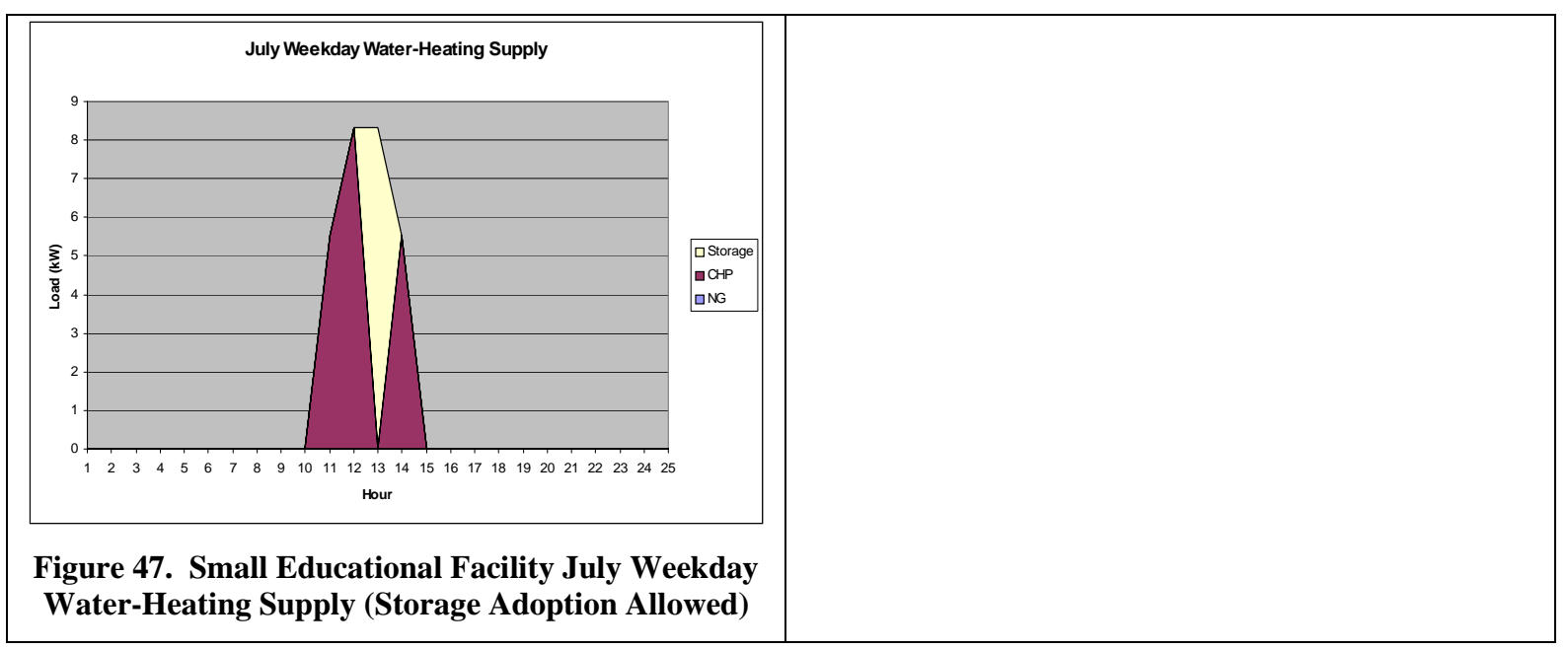

\subsection{Estimation of Heat Storage Costs}

In aggregate, the relationship between heat storage costs and capacity can be determined from the results of our analysis. Specifically, for each customer site, the cost reduction (in US\$) from the DER without heat storage case to the DER with heat storage case is plotted with the heat storage capacity (in $\mathrm{kWh}$ ) as indicated by the maximum total daily heating and cooling load. An ordinary-least squares (OLS) regression is then performed to yield a best-fit line to the data (see Figure 48). The slope of the OLS regression line will then indicate the average value in US\$ of a $\mathrm{kWh}$ of heat storage capacity.

Using the results for the ten San Francisco test sites, we find that heat storage capacity is valued, on average, at US\$1.25/kWh. Overall, test sites with greater capacity needs will be able to justify the investment because of the greater cost savings that result. Intuitively, the greater the heating requirements, the greater the value of the heat storage unit. While this relationship holds in aggregate, there are some exceptions, viz., the large educational facility (see Table 13). Unlike the other large facilities, the fraction of cumulative heating and cooling loads met by heat storage for this site is rather low, i.e., less than $20 \%$. This is due largely to the fact that it has a very low electricity-only load factor (see Figure 49), which implies that it needs to maintain onsite generation. In effect, the high cost of purchasing a large amount of electricity from the utility during on-peak hours dominates any cost savings from potentially fewer natural gas purchases. Therefore, unlike the sites examined in Sections 4.2 and 4.3, there is no clear-cut advantage to lowering on-site generation during on-peak hours via greater use of heat storage (or a combination of storage and absorption cooling in case of the cooling load). Consequently, the use of heat storage is secondary and limited mostly to off-peak hours, thereby resulting in a lower economic benefit. Finally, the fact that the unit is free may distort its adoption decision, i.e., it may be adopted even if it is sparingly used.

Table 13. Energy Cost Savings From Heat Storage Capacity

\begin{tabular}{l|l} 
Site & Storage Capacity (kWh) Cost Savings (US\$)
\end{tabular}




\begin{tabular}{c|cc}
\hline Small Merc & 0 & 0 \\
Small Office & 1640 & 1386 \\
Small Lodging & 2338 & 2255 \\
Small Educational & 2394 & 1145 \\
Large Merc & 2639 & 1388 \\
Large Office & 3681 & 4043 \\
Small Healthcare & 4962 & 6051 \\
Large Healthcare & 8382 & 12143 \\
Large Educational & 10018 & 4514 \\
Large Lodging & 10039 & 17276 \\
\hline
\end{tabular}

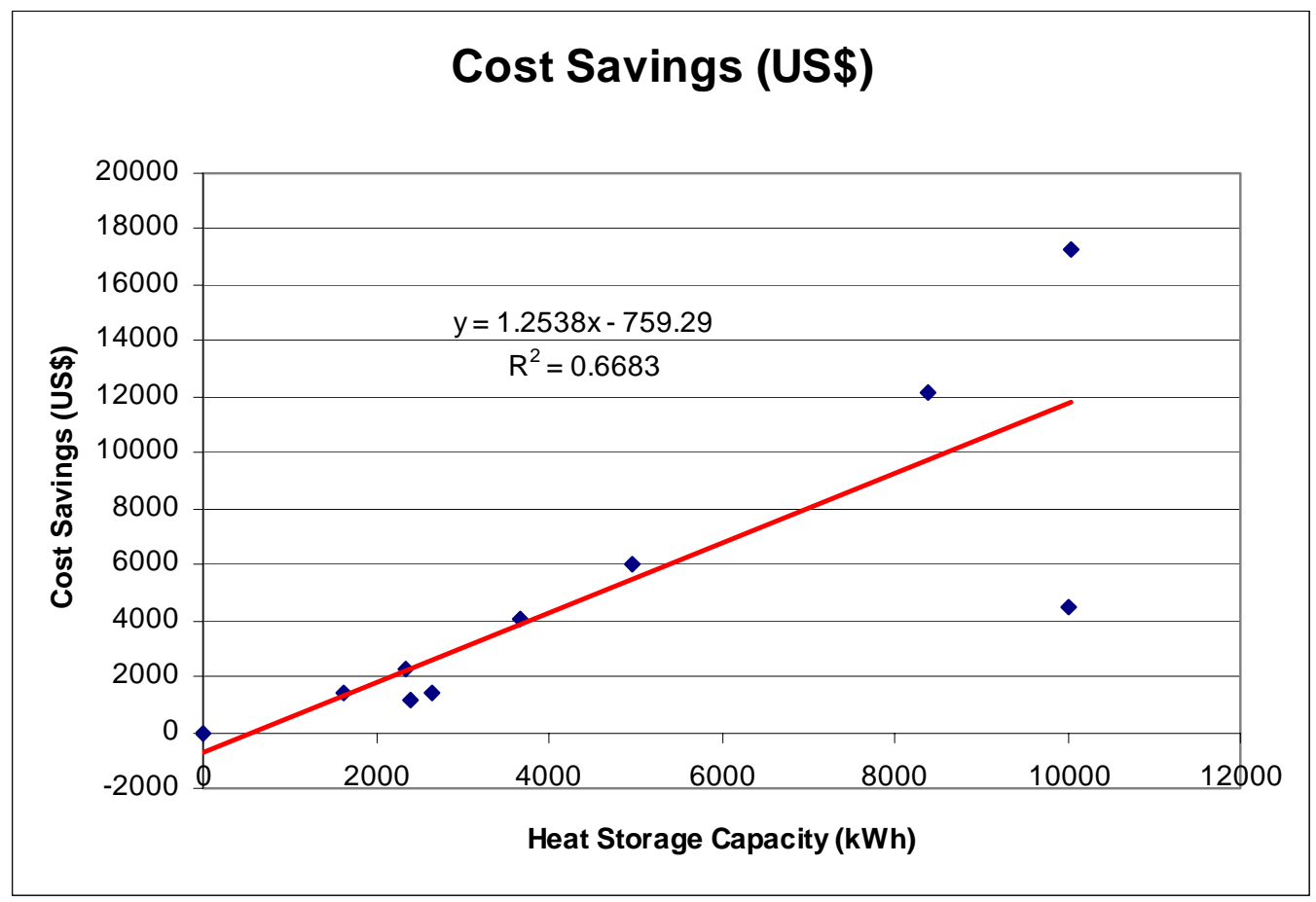

Figure 48. Energy Cost Savings From Heat Storage Capacity 


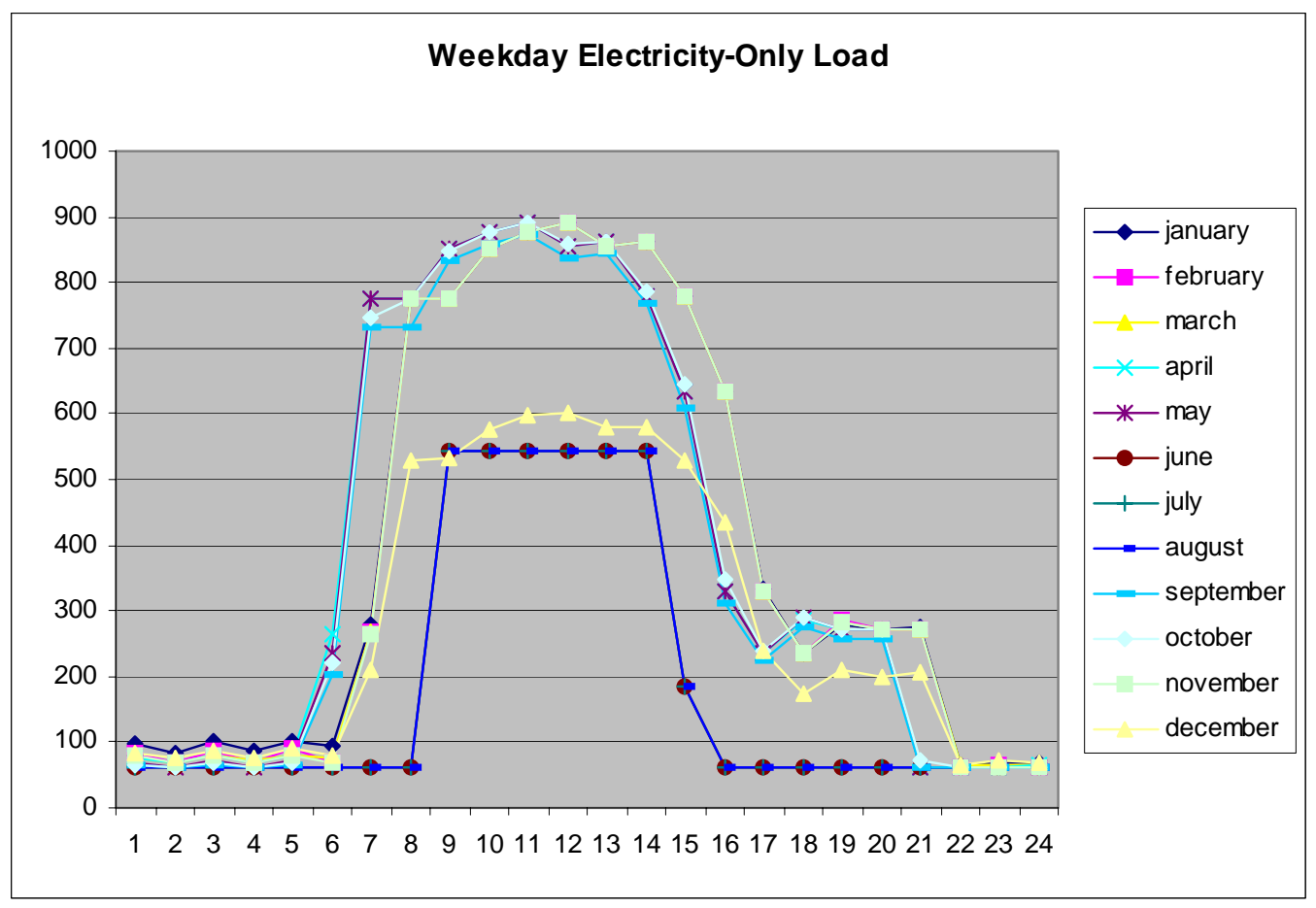

Figure 49. Large Educational Facility Weekday Electricity-Only Load

\section{Conclusions}

On-site generation of electricity via DER located close to the loads offers certain customers with the option to circumvent many of the drawbacks of centralised production of energy. In particular, DER enables energy needs to be met more reliably and at a lower cost than with centralised generation. Since we consider the adoption of DER from a strictly cost-minimising perspective, we do not account for its additional reliability. However, DER is advantageous to centralised generation, which has a significant fraction of its costs resulting from transmission and distribution of electricity.

This advantage of DER is amplified when CHP applications are included in the analysis. Indeed, the use of recovered heat tilts the balance in favour of DER since it allows heating loads to be met essentially for free. While our previous efforts in this area included the use of recovered heat for heating end uses, we did not allow for heat storage over time. In this paper, we extend our model to explore this possibility for a set of representative test sites in the San Francisco region.

In order to determine the suitability of heat storage, we examine the conditions under which it is economically beneficial to deploy. Not surprisingly, we find that for a site with a small heating load, there is no incentive to use heat storage. In fact, even a HX or AC is not beneficial to adopt. On the other hand, a customer with a medium ratio of heating to electricity loads uses heat storage to meet $30 \%$ of the heating loads and $10 \%$ of the cooling load. The heat storage unit works in tandem with the HX and AC by enabling the use of stored heat during mid- and off-peak hours and reducing the need for on-site generation. The site is then able to take advantage of relatively 
inexpensive utility purchases during these hours to meet its electricity-only load. As for the test site with a high ratio of cumulative heating to electricity loads, about $60 \%$ of the heating loads are met via heat storage. Since no AC is installed, heat storage does not benefit the cooling load. Again, there is decreased on-site generation during mid- and off-peak hours as the constraint to generate in order to meet heating loads with stored heat is relaxed. However, since some of the heating load is met directly via natural gas in the case without heat storage, the availability of heat inventories enables stored heat to be used for this purpose. The resulting displacement of natural gas purchases contributes as much to the cost savings as the savings from on-site generation.

By performing this analysis across a range of sites, we also provide a crude measure of the economic benefit resulting from an extra kWh of heat storage capacity. Overall, there is a persistent linear relationship between the value of heat storage and its capacity. Specifically, we find that each additional $\mathrm{kWh}$ of heat storage capacity lowers energy costs by US\$1.25 on average. The one exception to this is the large educational facility, which has a low electricity load factor. This requires it to maintain its on-site generation during on-peak hours, the savings from which dwarf any savings from lower natural gas purchases.

In this paper, we have circumvented the constraint that recovered heat must be used immediately by allowing for heat storage with losses from dissipation. The approach, however, is kept simple in order to ease implementation and the revelation of intuitive insights. In future work, we would like to examine a more realistic framework in which overnight heat storage is possible along with incorporation of ambient and water temperature properties to gauge more accurately the effect of heat lags. Comparison of the results for the San Francisco test sites with those in a more seasonal climate, such as that of Chicago, would also be interesting. An additional challenge would be to incorporate storage of electrical power via batteries alongside stored heat.

\section{References}

Blair, Tony (2004), Speech at the 10th Anniversary of His Royal Highness' Business and the Environment Programme, 14 September.

Brown, Daryl R (2000), "Thermal Energy Storage for Space Cooling, "Pacific Northwest National Laboratory Report PNNL-13607, Richland, WA, USA.

DOE (2000), DOE-2 Program Manual, http://gundog.lbl.gov/dirpubs/BASIC/basiclist.html (last accessed August 2001).

Energy Information Administration (2003), "2003 Commercial Buildings Energy Consumption Survey," http://www.eia.doe.gov/emeu/cbecs/contents.html (last accessed July 2005).

Energy Information Administration (2005), Annual Energy Outlook 2005, DOE/EIA0383, Washington, DC, USA. 
Firestone, Ryan (2005), "Distributed Energy Resources Customer Adoption Model Technology Data," LBNL, Berkeley, CA, USA (available online at http://der.lbl.gov/data/DERCAMTechDataOnline.pdf, last accessed July 2005).

Goldstein, Larry, Bruce Hedman, Dave Knowles, Steven I Freedman, Richard Woods, and Tom Schweizer (2003), "Gas-Fired Distributed Energy Resource Technology Characterizations," National Renewable Energy Laboratory Report NREL/TP-62034783, Golden, CO, USA.

Gumerman, Etan Z, Ranjit R Bharvirkar, Kristina Hamachi LaCommare, and Chris Marnay (2003), "Evaluation Framework and Tools for Distributed Energy Resources," Lawrence Berkeley National Laboratory Report LBNL-52079, Berkeley, CA, USA.

Hittle, Douglas C (2002), "Phase Change Materials in Floor Tiles for Thermal Energy Storage, " working paper, Colorado State University, Fort Collins, CO, USA

Huang, Joe, Hashem Akbari, Leo Rainer, and Ron Ritschard (1991), "481 Prototypical Commercial Buildings for Twenty Urban Market Areas," Lawrence Berkeley National Laboratory Report LBNL-29798, Berkeley, CA, USA.

Kedl, RJ (1991), "Wallboard with Latent Heat Storage for Passive Solar Applications," Oak Ridge National Laboratory Report ORNL/TM-11541, Oak Ridge, TN, USA.

Lawrence Berkeley National Laboratory (LBNL 2005), "Tariff Analysis Project," http://tariffs.lbl.gov/ (last accessed July 2005),

Marnay, Chris, Joseph Chard, Kristina Hamachi, Timothy Lipman, Mithra Moezzi, Boubékeur Ouaglal, and Afzal S Siddiqui (2001), "Modeling of Customer Adoption of Distributed Energy Resources," Lawrence Berkeley National Laboratory Report LBNL-49582, Berkeley, CA, USA.

Nash, Stephen G and Ariela Sofer (1996), Linear and Nonlinear Programming, McGraw-Hill, New York, NY, USA.

Rubio, F Javier, Afzal S Siddiqui, Chris Marnay, and Kristina Hamachi (2001), "CERTS Customer Adoption Model," Lawrence Berkeley National Laboratory Report LBNL-47772, Berkeley, CA, USA.

Siddiqui, Afzal S, Chris Marnay, Owen Bailey, and Kristina Hamachi LaCommare (2005a), "Optimal Selection of On-Site Power Generation with Combined Heat and Power Applications," International Journal of Distributed Energy Resources, 1(1): 33-62.

Siddiqui, Afzal S, Chris Marnay, Jennifer L Edwards, Ryan M Firestone, Srijay Ghosh, and Michael Stadler (2005b), "Effects of a Carbon Tax on Combined Heat and Power Adoption by a Microgrid," Journal of Energy Engineering, 131(1): 2-25. 